\title{
Gestión humana socialmente responsable en cooperativas de trabajo asociado colombianas
}

\author{
Alina Marcela Bustamante Salazar
}

RESUMEN: En los últimos años ha habido un creciente interés en estudiar la relación entre la responsabilidad social y la gestión humana dando origen a la gestión humana socialmente responsable. El objetivo de esta investigación es conceptualizar la gestión humana socialmente responsable en el contexto de las cooperativas de trabajo asociado colombianas, desde una perspectiva que integra el enfoque de las capacidades de Amartya Sen y los principios cooperativos, para comprender cómo las prácticas de gestión humana desarrollan diferentes capacidades de los asociados. Para lograr este propósito se realizó una investigación de enfoque cualitativo, basado en el estudio de casos múltiple y la teoría fundamentada. A partir de los resultados de la investigación, la gestión humana socialmente responsable en las cooperativas de trabajo asociado se define como un conjunto de prácticas, fundamentadas en los principios cooperativos, que están orientadas a desarrollar las capacidades de agencia, de bienestar y de solidaridad de los asociados, a través de la información, la formación, la participación, las condiciones de trabajo, la salud y la seguridad laboral, la igualdad de oportunidades y el balance trabajo-familia, para empoderarlos como trabajadores, propietarios y gestores de la cooperativa; proporcionando oportunidades laborales, económicas y sociales que contribuyan a su bienestar y les permita ser y hacer lo que consideran valioso para sus vidas; y de proyección a la comunidad a través de la información y la formación. Para lograr este propósito es necesario tener en cuenta las condiciones personales, organizacionales y del entorno externo que afectan estas prácticas, el cumplimiento de los principios cooperativos y el desarrollo de las capacidades de los asociados.

PALABRAS CLAVE: Gestión humana socialmente responsable, cooperativas de trabajo asociado, principios cooperativos, gestión humana, responsabilidad social, enfoque de las capacidades, teoría fundamentada.

CLAVES ECONLIT: M12, M14, 015, P13.

Cómo citar este artículo / How to cite this article: BUSTAMANTE, A.M. (2019): "Gestión humana socialmente responsable en cooperativas de trabajo asociado colombianas", CIRIEC-España, Revista de Economía Pública, Social y Cooperativa, 95, 217-255. DOI: 10.7203/CIRIEC-E.95.10433.

Correspondencia: Alina Marcela Bustamante Salazar, Doctora en Administración - Universidad EAFIT (MedellínColombia). Correo electrónico: alibs77@gmail.com. 


\section{EXPANDED ABSTRACT}

\section{Socially responsible human resource management in colombian worker cooperatives}

In the recent years there has been an increasing interest in studying the relationship between social responsibility and human resource management. Giving rise to socially responsible human resource management, a field of study aiming to integrate the developments of social responsibility and human resource management. The perspectives adopted in order to understand each one of these aspects and the emphasis on each other, influence the approaches, ideas and objectives conferred to socially responsible human resource management.

Theoretical debates about this relationship between social responsibility and human resource management are based mainly on an instrumental perspective, emphasizing one of both fields in an attempt to understand how human resource management helps to manage the social responsibility of the organizations, or how the latter helps to achieve the organizational goals of the human resource management areas. From a social integrative perspective, the main issue is to find a meeting point, that is, a concept and an objective that allows to integrate both fields of study.

The objective of this research is to conceptualize the socially responsible human resource management in the context of Colombian worker cooperatives from a perspective that integrates the Amartya Sen' capability approach and the cooperative principles in order to understand how the practices in human resource management develop different capabilities in each associate. From capability approach, this research proposes that the objective of the socially responsible human resource management be the development of the associates' capabilities of agency, well-being and solidarity. This is achieved through the human resource management practices that these cooperatives use and that translate the cooperative principles into actions. The human resource management practices analyzed are the ones included in the main international standards of social responsibility that place an emphasis in the labor dimension and in the researches carried out by several authors interested in the topic, which are: information, training, participation, work conditions, health and safety at work, equality of opportunities, and work-family balance. However, these practices, seen from this research, acquire a new meaning as practices of empowerment, well-being and projection to community because they have one objective: the development of the capabilities of each associate.

In order to achieve this objective, a qualitative research was carried out based on the grounded theory and the multiple case study of three Colombian worker cooperatives of the textile-manufacturing sector. The data was gathered using semi-structured interviews, group workshops, and bibliographical review and were analyzed using the grounded theory methodology with the help of the Atlas.ti software, version 7 . 
Thanks to this research, it was possible to find out that the information, training, participation and equality of opportunity practices contribute to the associate's empowerment and help in the development of their agency capability; that is, they strengthen their autonomy and responsibility as cooperative workers, owners and managers.

While the prevailing literature assesses the worker well-being in terms of organizational commitment, job satisfaction and performance, this research suggests a different conception in order to study the well-being practices in terms of work, economic and social opportunities offered to the associates through training, participation, work conditions, health and safety at work, and work-family balance. These practices help to develop the well-being capability. This implies a focus change in the understanding of well-being.

In the current literature about social responsibility and human resource management, some authors consider that the information and training practices evolve into practices of projection towards the community, situation that has been demonstrated in this study. These practices contribute to the development of solidarity capability. This research proposes the solidarity capability as a new dimension to be considered in the Amartya Sen' capability approach. The level of analysis used by Sen is the individual, who develops the agency capability when he acts autonomously and takes responsibility of his actions. The findings of this research indicate that responsibility is a concept that lies beneath the worker cooperative associates' agency and solidarity capabilities, but occurs in different perspectives: individual (agency capability), and collective (solidarity capability). Thus, solidarity capability implies the recognition of the bonds that connect associates with a collective of people: the cooperative and the community, and, as member of these collectives, it is important to take responsibilities.

Based on the findings of this research, socially responsible human resource management in worker cooperatives is defined as a set of practices based in the cooperative principles aimed to the development of the agency, well-being and solidarity capabilities of associates through information, training, participation, work conditions, health and safety at work, equality of opportunities, and work-family balance in order to empower them as workers, owners and managers of the cooperative, providing job, economic and social opportunities that contribute to their well-being and allow them to be and do what they believe is better for their lives, and allowing the projection towards community through information and training. In order to achieve this purpose, it is necessary to take into account the personal, organizational and environmental conditions that affect these practices, the compliance of the cooperative principles and the development of associates' capabilities.

There are personal conditions such academic level, health status and familial commitments. Other conditions arise from the dynamic of the cooperative organization, such as the work methods, the relationships between associates and leaders, the intervention of third parties in the decisions of the cooperatives. While other conditions, as normativity and location, come from the environment in which these cooperatives function. Each condition has an impact in the human resource management practices used by the cooperatives and in the development of the associates' capabilities. The challenge 
for the associates is to recognize and transform these conditions and to decide which ones favor or block their opportunities for achieving the life they want.

The data analyzed allow to conclude that it is possible to perform a socially responsible human resource management in the Colombian worker cooperatives of the textile-manufacturing sector when they work following the cooperative principles, which are constituted in their creation and contribute to the empowerment and well-being of associates and to the projection towards the community, developing in them an agency, well-being and solidarity capability. Likewise, they are able to achieve their Mission through the creation of stable job opportunities, granting associates with additional work conditions to the ones legally established, providing well-being to associates and their families and projecting themselves towards the communities through information and training practices. However, it is necessary to boost the information practices aimed to the community and to make public the socially responsible human resource management practices that cooperatives execute in order to draw attention to the organization contributions for the development of the people and community of the place where they are. In addition, this will help to the understanding and recognition of the worker cooperatives as a legitimate model of entrepreneurship.

The socially responsible human resource management conceptualization proposed in this research takes on different perspectives to the ones traditionally used. On one hand, it builds a social integrative perspective based in the capability approach, human resource management practices in the context of social responsibility and cooperative principles. On the other, it adopts a multi-level focus that helps to understand how the cooperative principles -institutional level - translate into human resource management practices - organization level-and help to explain the consequences of these practices in the development of the associates' capabilities -individual level-.

There are some limitations to this work. The study context is focused in Colombian worker cooperatives of the textile-manufacturing sector, future researches could replicate this study's theoretical proposals for analyzing the worker cooperatives of different economic sectors, different countries or other types of cooperatives, or for carrying out comparative studies with other kinds of companies. Moreover, the conceptualization of the associates' agency, well-being and solidarity capabilities has been developed in theoretical terms, future studies could use or analyze these capabilities from a quantitative approach.

KEYWORDS: Socially Responsible Human Resource Management, Worker Cooperatives, Cooperative Principles, Human Resource Management, Social Responsibility, Capability Approach, Grounded Theory. 


\section{Introducción}

En los últimos años se ha desarrollado un interés en estudiar la relación entre la responsabilidad social (RS) y la gestión humana (GH) (Shen, 2011; Shen y Zhu, 2011; Morgeson, Aguinis, Waldman y Siegel, 2013). La mayor parte de la literatura que integra ambos campos académicos enfatiza en el estudio de las motivaciones que tienen las organizaciones para implementar iniciativas de RS (Cooke y He, 2010); los ámbitos de aplicación y campos de actuación de la RS en la gestión laboral (Celma, Martínez-Garcia y Coenders, 2014; Barrena-Martínez, López-Fernández y Romero-Fernández, 2017).

Casi todos los estudios se centran en comprender la relación RS y GH desde el punto de vista de la empresa, algunos autores analizan las contribuciones de las áreas de $\mathrm{GH}$ al liderazgo responsable (Gond, Igalens, Swaen y El-Akremi, 2011) y al cumplimiento de los propósitos de RS de las empresas (Calderón, Álvarez y Naranjo, 2011; García, Azuero y Peláez, 2013).

Los debates teóricos de esta relación entre RS y $\mathrm{GH}$, se fundamentan principalmente en una perspectiva instrumental, haciendo énfasis en uno de los dos campos (Voegtlin y Greenwood, 2016), tratando de comprender cómo GH ayuda a gestionar la RS de las organizaciones, o cómo la RS ayuda a lograr los objetivos organizacionales de las áreas de GH. Desde una perspectiva de integración social, el asunto central es encontrar un punto de convergencia, esto es, un concepto y una finalidad que permita integrar ambos campos de estudio.

El objetivo de esta investigación es conceptualizar la gestión humana socialmente responsable en el contexto de las cooperativas de trabajo asociado (CTA) colombianas, desde una perspectiva de integración social, basada en el enfoque de las capacidades de Amartya Sen y los principios cooperativos, para comprender cómo las prácticas de gestión humana desarrollan diferentes capacidades de los asociados. Para lograr este propósito se realizó una investigación de enfoque cualitativo, basado en la teoría fundamentada y el estudio de caso múltiple de tres cooperativas de trabajo asociado colombianas del sector textil-confección.

Desde el enfoque de las capacidades de Amartya Sen, esta investigación propone que la finalidad de la gestión humana socialmente responsable es el desarrollo de las capacidades de agencia, bienestar y solidaridad de los asociados, esto se logra a través de las prácticas de GH que las cooperativas realizan y mediante las cuales traducen en acciones los principios cooperativos. Las prácticas de GH analizadas son aquellas incluidas en los principales estándares internacionales de RS que enfatizan en la dimensión laboral y en las investigaciones realizadas por autores interesados en el tema (Celma, et al., 2014), (Barrena-Martínez, et al., 2017), éstas son: la información, la formación, la participación, las condiciones de trabajo, la salud y seguridad laboral, la igualdad de oportunidades y el 
balance trabajo-familia. No obstante, estas prácticas vistas desde la propuesta de esta investigación asumen un nuevo significado, como prácticas de empoderamiento de los asociados, prácticas de bienestar de los asociados y prácticas de proyección a la comunidad, pues atienden a una finalidad: el desarrollo de las capacidades de los asociados.

La conceptualización de la gestión humana socialmente responsable que se propone en este trabajo, asume perspectivas diferentes a las que tradicionalmente se han utilizado y por lo tanto realiza varias contribuciones. En primer lugar, se atiende al llamado de Voegtlin y Greenwood (2016) respecto a la necesidad de realizar investigaciones cualitativas, desde una perspectiva de integración. En segundo lugar, se asume un enfoque multinivel (Aguinis y Glavas, 2012), que ayuda a comprender cómo los principios cooperativos -nivel institucional- se traducen en prácticas de gestión humana -nivel organizacional- y explicar las implicaciones de esas prácticas en el desarrollo de las capacidades de los asociados -nivel individual-.

El artículo está estructurado del siguiente modo, después de esta introducción que explica el problema de investigación se presentan el marco teórico, la metodología y los resultados. Finalmente, se plantean las conclusiones, limitaciones y futuras investigaciones derivadas de este estudio.

\section{Marco teórico}

2.1 Gestión humana y responsabilidad social: una integración a través del enfoque de las capacidades

En los últimos años ha habido un creciente interés en estudiar los nexos entre la RS y la GH (Voegtlin y Greenwood, 2016) dando origen a la gestión humana socialmente responsable, ésta es un campo de investigación que se propone integrar los desarrollos de la RS y la GH. Las perspectivas que se adoptan para comprender cada una de éstas y el énfasis que se hace en una u otra, inciden en los enfoques, las concepciones y las finalidades que se le atribuyen a la gestión humana socialmente responsable.

En relación con la RS, es preciso reconocer que se carece de un concepto único y universal (Rodríguez, Moyano y Jiménez, 2015), sin embargo, la Comisión Europea (2011) define la RS como "un proceso destinado a integrar las preocupaciones sociales, medioambientales y éticas, el respeto de los derechos humanos y las preocupaciones de los consumidores en sus operaciones empresariales y su estrategia básica, a fin de: i) maximizar la creación de valor compartido para sus propieta- 
rios/accionistas y para las demás partes interesadas y la sociedad en sentido amplio; ii) identificar, prevenir y atenuar sus posibles consecuencias adversas".

Según esta definición, la RS implica reconocer que las organizaciones como actores de la sociedad asumen obligaciones con los grupos de interés que se benefician o se afectan con las acciones que éstas realizan. Tal como lo señalan García, et al. (2013) las mayores posibilidades de intervención desde la RS se concentran en los grupos de interés interno, es decir, en los trabajadores, a través de la gestión humana socialmente responsable.

En relación con la GH, existen diferentes concepciones o modelos de GH. La concepción "hard" 0 modelo de cumplimiento, considera el personal como un recurso más de la organización, que debe ser administrado de manera eficiente y flexible, con criterios de minimización de costos y el cumplimiento de estándares de desempeño para lograr los objetivos de la organización (Guest, 1987). Y la concepción "soft" o modelo relacional, considera que las personas son lo más valioso de una organización, por lo tanto se requiere un enfoque pluralista en la gestión del personal que integre los objetivos de la organización y las demandas sociales de los trabajadores, de modo que los resultados organizacionales van más allá de los aspectos económicos para incluir el bienestar de los trabajadores y de la sociedad en general (Rhodes y Harvey, 2012).

Voegtlin y Greenwood (2016) realizan una revisión de la literatura sobre gestión humana socialmente responsable e identifican tres perspectivas utilizadas en las investigaciones sobre este tema: instrumental, política y de integración social.

En la perspectiva instrumental, la implicación de los trabajadores en la RS es un instrumento para lograr los objetivos económicos de las organizaciones. Los debates teóricos de esta relación entre RS y GH hacen énfasis en uno de los dos campos, se fundamentan en los enfoques económicos neoclásicos y en la concepción "hard" de GH, tratando de comprender cómo la RS ayuda a lograr los objetivos organizacionales de las áreas de GH o cómo la GH ayuda a gestionar la RS de las organizaciones, y las implicaciones en el desempeño de las empresas. La perspectiva política enfatiza en el poder que las organizaciones ejercen en la sociedad y el uso responsable de éste, reconoce que existen conflictos de interés entre las partes implicadas y que las prácticas de gestión humana socialmente responsable pueden contribuir a resolver estos conflictos. La perspectiva de integración social se fundamenta en la concepción "soft" de la GH, analiza cómo se relacionan la RS y la GH para crear beneficios para los trabajadores, la organización y sus grupos de interés. Al respecto, Voegtlin y Greenwood (2016) consideran necesario realizar investigaciones cualitativas que ayuden a comprender cómo las prácticas de gestión humana socialmente responsable contribuyen a crear beneficios para los grupos de interés, así como las condiciones que favorecen o dificultan estas prácticas.

Los autores que han estudiado las prácticas de gestión humana socialmente responsable (Celma et al., 2014; Barrena-Martínez et al., 2017) se basan en algunas iniciativas internacionales de RS en lo referente a las prácticas laborales, tales como las declaraciones de la ONU y la OIT sobre derechos 
humanos y principios fundamentales del trabajo, las directrices de la OCDE, los estándares ISO 26000 y SA 8000 . Estos se constituyen en parámetros para una gestión humana socialmente responsable, que incluyen aspectos relacionados con los derechos de los trabajadores generalmente contemplados en las leyes laborales, así como otras iniciativas voluntarias para mejorar el bienestar de los trabajadores, más allá de lo exigido por la normatividad (Celma et al., 2014).

Además de los estándares internacionales mencionados, para el propósito de esta investigación, se realizó una revisión de la literatura, identificando aquellas prácticas que habían sido estudiadas por otros autores interesados en la relación entre RS y GH, entre las cuales se encuentran la información, la formación, la participación, las condiciones de trabajo, la salud y seguridad laboral, la igualdad de oportunidades y el balance trabajo-familia, las cuales se analizan en esta investigación. En la Tabla 1 se definen estas prácticas y se identifican los estudios previos.

Este trabajo se inscribe en una perspectiva de integración social (Voegtlin y Greenwood, 2016), basada en el enfoque de las capacidades propuesto por el Nobel de Economía Amartya Sen ${ }^{1}$, con el propósito de comprender cómo las prácticas de gestión humana anteriormente mencionadas ayudan a desarrollar las capacidades de las personas.

Los funcionamientos y las capacidades son los conceptos nucleares que fundamentan este enfoque. Los funcionamientos representan los logros de una persona, lo que ésta es capaz de ser o hacer, éstos abarcan funciones básicas como estar bien nutrido, tener buena salud o referirse a funciones más complejas como ser feliz, tener dignidad, participar en la vida de la comunidad (Sen, 1995:53). Las capacidades representan las oportunidades reales, el conjunto de funcionamientos que la persona puede alcanzar y de los cuales puede elegir, son el reflejo de las libertades que ésta dispone para llevar el tipo de vida que valora. Ambos conceptos se relacionan, pero proporcionan "diferentes tipos de información, el primero [funcionamiento] sobre las cosas que hace una persona y el segundo [capacidad] sobre las cosas que tiene libertad fundamental para hacer" (Sen, 2006:100).

El desarrollo de las capacidades se logra a través de las libertades que disfrutan las personas, Amartya Sen define cinco libertades instrumentales: libertades políticas, oportunidades económicas, oportunidades sociales, garantías de transparencia y seguridad protectora. Las libertades políticas se refieren a los derechos y oportunidades que tienen las personas para participar democráticamente en los asuntos de interés comunitario, relacionados con las decisiones de quiénes y cómo ejercer el gobierno, las oportunidades de expresión y en general lo relacionado con los derechos humanos. Las oportunidades económicas se relacionan con las facilidades de acceso a los recursos económicos que permiten a las personas consumir, producir o realizar intercambios. Las oportunidades sociales

1.- Al desarrollo posterior del enfoque de las capacidades han aportado otros autores, una de las contribuciones más sobresalientes es la realizada por Martha Nussbaum. Sin embargo, es necesario reconocer que existen algunos puntos de divergencia entre la propuesta de Sen y la perspectiva de Nussbaum, para ampliar este asunto puede consultarse Urquijo (2008). En esta investigación se trabaja desde los planteamientos de Amartya Sen. 


\section{Tabla 1. Prácticas de gestión humana y responsabilidad social estudiadas}

\begin{tabular}{|c|c|c|}
\hline PRÁCTICA & DEFINICIÓN & ESTUDIOS PREVIOS \\
\hline Información & $\begin{array}{l}\text { Está orientada a suministrar a los asociados los datos contex- } \\
\text { tualizados acerca de la cooperativa y de su entorno, para que } \\
\text { puedan participar en la toma de decisiones. }\end{array}$ & $\begin{array}{l}\text { García, et al. (2013); Celma, et al. } \\
\text { (2014); Barrena-Martínez, et al. } \\
\text { (2017) }\end{array}$ \\
\hline Formación & $\begin{array}{l}\text { Su finalidad es desarrollar las capacidades de los asociados y los } \\
\text { miembros de la comunidad, para que puedan participar en la coo- } \\
\text { perativa como trabajadores, propietarios y gestores y además, } \\
\text { para que logren ser y hacer lo que consideren valioso para sus } \\
\text { vidas. }\end{array}$ & $\begin{array}{l}\text { Cooke y He (2010); Shen (2011); } \\
\text { Shen y Zhu (2011); García, et al. } \\
\text { (2013); Celma, et al. (2014); Barrena- } \\
\text { Martínez, et al. (2017) }\end{array}$ \\
\hline Participación & $\begin{array}{l}\text { Implicación de los asociados en la gestión de la cooperativa, a } \\
\text { través de procesos democráticos y en los aspectos económicos, } \\
\text { mediante aportes de capital y la participación en los resultados. }\end{array}$ & $\begin{array}{l}\text { Cooke y He (2010); Shen (2011); } \\
\text { Shen y Zhu (2011); García, et al. } \\
\text { (2013); Celma, et al. (2014); Barrena- } \\
\text { Martínez, et al. (2017) }\end{array}$ \\
\hline $\begin{array}{l}\text { Condiciones de } \\
\text { trabajo }\end{array}$ & $\begin{array}{l}\text { Prácticas tendientes a proporcionar los medios técnicos y tec- } \\
\text { nológicos, instalaciones y servicios necesarios para que los aso- } \\
\text { ciados realicen su trabajo y el reconocimiento de los derechos } \\
\text { acordados en los regímenes de trabajo asociado, en la normati- } \\
\text { vidad que regula las cooperativas, así como beneficios adiciona- } \\
\text { les a los exigidos legalmente. }\end{array}$ & $\begin{array}{l}\text { Cooke y He (2010); Shen y Zhu } \\
\text { (2011); García, et al. (2013); Barrena- } \\
\text { Martínez, et al. (2017) }\end{array}$ \\
\hline $\begin{array}{l}\text { Salud y seguri- } \\
\text { dad laboral }\end{array}$ & $\begin{array}{l}\text { Su finalidad es preservar y mejorar la salud e integridad física y } \\
\text { mental de los asociados a través del establecimiento de condi- } \\
\text { ciones ambientales, programas y métodos de trabajo adecuados. }\end{array}$ & $\begin{array}{l}\text { Cooke y He (2010); Shen (2011), } \\
\text { Shen y Zhu (2011); García, et al. } \\
\text { (2013); Celma, et al. (2014); Barrena- } \\
\text { Martínez, et al. (2017) }\end{array}$ \\
\hline $\begin{array}{l}\text { Igualdad de opor- } \\
\text { tunidades }\end{array}$ & $\begin{array}{l}\text { Reconocimiento de iguales deberes y derechos para los asocia- } \\
\text { dos, así como de oportunidades para ejercerlos. }\end{array}$ & $\begin{array}{l}\text { Cooke y He (2010); Shen (2011); } \\
\text { Shen y Zhu (2011); García, et al. } \\
\text { (2013); Celma, et al. (2014); Barrena- } \\
\text { Martínez, et al. (2017) }\end{array}$ \\
\hline $\begin{array}{l}\text { Balance trabajo } \\
\text { familia }\end{array}$ & $\begin{array}{l}\text { Están orientadas a facilitar a los asociados las condiciones de } \\
\text { tiempo, servicios y acompañamiento para atender actividades } \\
\text { relacionadas con su familia o compromisos personales }\end{array}$ & $\begin{array}{l}\text { Cooke y He (2010); Shen (2011); } \\
\text { Shen y Zhu (2011); García, et al. } \\
\text { (2013); Celma, et al. (2014); Barrena- } \\
\text { Martínez, et al. (2017) }\end{array}$ \\
\hline
\end{tabular}

FUENTE: Elaboración propia. 
se refieren a la posibilidad de acceso al sistema educativo y de sanidad que contribuye a mejorar la vida de las personas y las habilita para participar eficazmente en las actividades económicas y políticas. Las garantías de transparencia hacen alusión a la construcción de confianza necesaria para que las personas participen y la sociedad funcione de manera lícita y responsable. Éstas incluyen el derecho de divulgación de información. La seguridad protectora comprende los mecanismos institucionales fijos de protección social a los grupos más vulnerables de la población (Sen, 2006). En esta investigación se hizo énfasis en el análisis de las oportunidades económicas y sociales, recolectando información específica para estos conceptos; en cuanto a las libertades políticas y las garantías de transparencia como éstas hacen alusión a la participación democrática y la divulgación de información, respectivamente, se consideró conveniente analizarlas de un modo general como "prácticas de participación" y "prácticas de información".

Amartya Sen considera que el bienestar y la agencia constituyen dos aspectos de los seres humanos. El bienestar permite conocer el estado de una persona, los logros alcanzados. La agencia se refiere a la capacidad de elegir y perseguir las propias metas y valores (Urquijo, 2008:78-79). Desde el aspecto de agencia, los seres humanos se conciben como agentes, un agente es aquel capaz de tomar decisiones, actuar por sí mismo y asumir las responsabilidades que se derivan de sus decisiones. Por otra parte, desde el aspecto de bienestar las personas se conciben como beneficiarios cuyos intereses deben ser considerados (Sen, 1985:205).

Ambos aspectos cobran importancia en esta investigación, al analizar las prácticas de GH que las CTA implementan relacionadas con la información, la formación, la participación, la igualdad de oportunidades, se está enfatizando en la capacidad de agencia; de otro lado, al estudiar las condiciones de trabajo, la salud y seguridad laboral y el balance trabajo-familia se hace énfasis en la capacidad de bienestar.

En síntesis, Amartya Sen propone el enfoque de las capacidades como un marco de análisis para conceptualizar y evaluar diferentes asuntos sociales, como el bienestar, el desarrollo humano, la pobreza, la desigualdad, entre otros. No obstante, la aplicación de este enfoque no se limita a estos conceptos, en el campo administrativo Cameron y Eyeson (2012), Downs y Swailes (2013) consideran que este enfoque ayuda a integrar los asuntos de la $\mathrm{RS}$ y la $\mathrm{GH}$. Además, como el contexto de estudio de esta investigación son las CTA, los principios cooperativos se constituyen en un referente necesario para la conceptualización de la gestión humana socialmente responsable.

\subsection{Principios cooperativos como fundamento de la gestión humana socialmente responsable en las CTA}

Las cooperativas son asociaciones autónomas de personas que buscan satisfacer sus necesidades y aspiraciones económicas, sociales y culturales en común, mediante una empresa de propiedad conjunta y gestión democrática. Existen diferentes tipos de cooperativas y de criterios para 
agruparlas. Según las funciones de sus miembros se pueden identificar cooperativas de usuarios, de consumidores, de productores y de trabajo asociado.

Esta investigación estudia las cooperativas de trabajo asociado-CTA, éstas tienen como propósito generar y mantener puestos de trabajo sustentables que generen riqueza para mejorar la calidad de vida de los asociados y sus familias, dignificar el trabajo humano y promover el desarrollo comunitario y local (CICOPA - Comité Ejecutivo de la Organización Internacional de Cooperativas de Producción Industrial, 2005). Éstas se caracterizan porque los asociados desempeñan un triple rol, como trabajadores, propietarios y gestores de la cooperativa.

El segundo reporte global de cooperativas y empleo publicado por CICOPA, indica que en el mundo existen cerca de 2,94 millones de cooperativas, las cuales generan fuentes de empleo para 279,4 millones de personas, lo cual representa el 9,46\% de la población ocupada en el mundo (Hyungsik, 2017:24). Las CTA representan cerca del $8,61 \%$ del total de organizaciones cooperativas y generan más de 12 millones de puestos de trabajo (Terrasi y Hyungsik, 2017).

Las cooperativas se rigen por unas reglas de actuación conocidas como principios cooperativos, éstos han sido acogidos y difundidos en el contexto mundial por la Alianza Cooperativa Internacional, dichos principios son: i) adhesión voluntaria y abierta: pueden participar las personas dispuestas a usar los servicios de la cooperativa y aceptar las responsabilidades de ser asociado; ii) gestión democrática por parte de los asociados, estos participan democráticamente en la gestión y en la toma de decisiones; iii) participación económica de los asociados, éstos contribuyen equitativamente en la conformación del capital de la cooperativa y definen la distribución y uso de los excedentes; iv) autonomía e independencia, en las relaciones con terceros se debe garantizar el control democrático por parte de los asociados y la autonomía cooperativa; $v$ ) educación, formación e información, dirigida a los que participan como asociados, representantes, dirigentes y empleados para que puedan contribuir al desarrollo de la cooperativa e informar a la comunidad sobre la naturaleza y los beneficios de la cooperación; vi) cooperación entre cooperativas, trabajando conjuntamente para su fortalecimiento; vii) interés por la comunidad, aportando al desarrollo sostenible de las comunidades, de acuerdo a los criterios aprobados por los asociados (ACI - Alianza Cooperativa Internacional, 1995).

Algunos autores argumentan que las especificidades de las cooperativas, que se concretan en los principios cooperativos, hacen de estas organizaciones escenarios más propicios para el ejercicio de la RS (Mozas y Puentes, 2010; Server y Capó, 2011; Gadea, 2012; Gallardo-Vásquez, SánchezHernández y Castilla-Polo, 2015). No obstante, hace falta reconocer que la existencia de unos principios cooperativos, no es garantía que las organizaciones los cumplan, es necesario estudiar cómo se traducen en prácticas tales principios.

Las prácticas de gestión humana explicadas en la Tabla 1 constituyen una forma de poner en práctica los principios cooperativos. Así por ejemplo, las prácticas de información y formación son necesarias para la adhesión voluntaria y abierta por parte de los asociados y dar cumplimiento al principio 
de educación, formación e información. Las prácticas de participación, tal como lo señala Báez Melián (2011) implica el ejercicio de los derechos a participar en los beneficios, en la toma de decisiones y en la propiedad de la empresa, éstos se relacionan con los principios de participación económica y gestión democrática por parte de los asociados. A través del principio gestión democrática los asociados definen los regímenes de trabajo, de compensaciones y otras condiciones de trabajo, de salud y seguridad laboral aplicables en las CTA.

En síntesis, esta investigación se propone fundamentar el concepto gestión humana socialmente responsable en el contexto de las cooperativas de trabajo asociado, desde el enfoque de las capacidades y los principios cooperativos, a través del estudio de las prácticas de gestión humana y sus implicaciones en el desarrollo de las capacidades de los asociados, en tres organizaciones colombianas. Los principios cooperativos son el fundamento de la gestión humana socialmente responsable y resumen las particularidades del contexto organizacional objeto de estudio -CTA-. El enfoque de las capacidades permite la integración de la RS y la GH en torno a una finalidad común: el desarrollo de las capacidades de las personas. Las prácticas de gestión humana seleccionadas son aquellas incluidas en los estándares internacionales de RS que enfatizan en la dimensión laboral y en las investigaciones realizadas por autores interesados en el tema.

\section{Metodología}

La investigación es de enfoque cualitativo, basada en el estudio de casos. Éste es un método de investigación que permite estudiar un fenómeno que se presenta en un contexto específico para comprenderlo y construir teoría, aplicando la lógica de replicación. La información fue recolectada y organizada siguiendo el método de estudio de caso múltiple según la propuesta de Yin (2003). El análisis de los datos se realizó conforme a los procesos de la teoría fundamentada según el enfoque de Strauss y Corbin (2002); la característica esencial de este método es la emergencia de la teoría a partir de los datos, el marco teórico que usa el investigador es una guía para explorar en el terreno, a los conceptos se les debe permitir que emerjan de los datos.

En el desarrollo de la investigación se estudiaron tres organizaciones colombianas, seleccionadas atendiendo a los siguientes criterios: i) cooperativas de trabajo asociado del sector textil-confección; ii) con un número superior a 200 asociados; iii) con una trayectoria igual o superior a 10 años y iv) que los medios de producción fueran propiedad de las cooperativas. Al revisar la base de datos de la Superintendencia de la Economía Solidaria de Colombia se identificaron cuatro (4) cooperativas que cumplían estos criterios, sólo tres (3) de las cooperativas expresaron disponibilidad de participar en el estudio. Siguiendo los criterios propuestos por Yin (2003:47) se considera que tres casos per- 


\section{GESTIÓN HUMANA SOCIALMENTE RESPONSABLE EN COOPERATIVAS DE TRABAJO ASOCIADO COLOMBIANAS}

miten aplicar la lógica de replicación y obtener las evidencias para construir el concepto gestión humana socialmente responsable.

La decisión de estudiar las CTA colombianas, surge por la problemática que este sector ha enfrentado en años recientes. En Colombia, durante la década 2000-2010 se presentó un crecimiento inusitado de las CTA, este crecimiento se debió en buena parte a la instrumentalización de estas organizaciones para la subcontratación y degradación de las condiciones laborales de algunos trabajadores vinculados a actividades del sector público y privado (Álvarez y García, 2010); (Roelants, Hyungsik y Terrasi, 2014; Confecoop, 2017). Sin embargo, la aplicación de una normatividad a partir del año 2011 para impedir el uso indebido del cooperativismo de trabajo asociado ha generado restricciones para la operación y desarrollo de algunas CTA y una disminución de aproximadamente el $80 \%$ en el número de CTA [2500 CTA liquidadas] y de los puestos de trabajo relacionados (Terrasi y Hyungsik, 2017; Superintendencia de la Economía Solidaria, 2017). Estas situaciones han originado una estigmatización del modelo de cooperativismo de trabajo asociado, una concepción equivocada respecto de su naturaleza y propósito y una "persecución por parte de los gobiernos, sin distinguir entre las auténticas y las falsas [CTA]" (Cracogna, 2015:28)2.

Todo lo anterior amerita una intervención por parte de la academia para ayudar a comprender, desde una postura científica, las problemáticas de gestión que enfrentan estas organizaciones, en particular esta investigación se interesa en analizar la fundamentación de la gestión humana socialmente responsable en las CTA del sector textil-confección, este propósito es coherente con uno de los desafíos empresariales para el futuro de las cooperativas señalado por Roelants et al. (2014) en cuanto al fortalecimiento de la gestión humana en estas organizaciones.

La industria textil-confección es significativa para la economía colombiana, la producción del sector representa el 9,2\% en el PIB de la industria manufacturera (Superintendencia de Sociedades, 2015), aunque, la informalidad en las relaciones laborales de esta industria, hace difícil calcular con exactitud el número de puestos de trabajo que genera.

Recientes estudios han señalado el potencial de las CTA para contribuir en la formalización del empleo informal (Hyungsik, 2017). En Colombia la tasa de empleo informal es de 47,7\% (DANE, 2017), uno de los sectores más afectados por esta situación es la industrial textil-confección, que desde la década de 1990 comenzó un proceso de flexibilización de sus estructuras laborales y productivas, reemplazando las plantillas de trabajadores dependientes por acuerdos de subcontratación de la producción con CTA, medianos y pequeños talleres de confección, algunos de ellos caracterizados por la precariedad de las condiciones laborales. Esta investigación contribuye en la comprensión de las características de las oportunidades laborales que generan las CTA de este sector en Colombia, desde el ámbito de la gestión humana socialmente responsable.

2.- Pero, esta situación no es exclusiva de Colombia, en Brasil se presenta un panorama similar. 
El criterio de antigüedad de mínimo 10 años de trayectoria para la selección de las CTA incluidas en la investigación, está orientado al estudio de cooperativas con un grado de madurez y permanencia en el entorno. Según el estudio de Confecámaras (2016) el 70\% de las empresas creadas en Colombia fracasan durante los primeros cinco años de vida, el periodo de consolidación de una empresa se lleva a cabo entre el $5^{\circ}$ y el $10^{\circ}$ año. De otro lado, uno de los criterios para evaluar el tamaño de las empresas es el número de trabajadores, en Colombia se consideran grandes empresas aquellas con más de 200 trabajadores, estas empresas tienen mayor probabilidad de supervivencia (Confecámaras, 2017) y generalmente tienen un área o persona responsable de la gestión humana, la cual se constituye en objeto de estudio en esta investigación.

La propiedad sobre los medios de trabajo es otro criterio utilizado para la selección de los casos analizados en esta investigación, esto permite a las CTA una mayor autonomía (Álvarez y García, 2010), y para el caso colombiano, es uno de los asuntos que ayuda a distinguir a las pseudocooperativas de las legítimas, éstas suelen tener la propiedad de los medios de trabajo, mientras en las primeras no hay propiedad de los mismos, porque se dedican ilegalmente a la intermediación laboral, enviando a sus asociados a trabajar en las plantas de producción de las empresas de textil-confección contratantes. Por tal razón, para evitar incluir en la muestra de esta investigación esas pseudocooperativas se hizo una verificación de la propiedad sobre los medios de trabajo, a través de una visita a las plantas de producción de las cooperativas seleccionadas para el estudio. La Tabla 2 resume algunos datos de los casos estudiados ${ }^{3}$.

\section{Tabla 2. Datos generales de los casos estudiados}

\begin{tabular}{|l|c|c|c|}
\hline CRITERIO & CASO 1 & CASO 2 & CASO 3 \\
\hline Ubicación & Antioquia & Valle del Cauca & Antioquia \\
Año de creación & 1984 & 1974 & 2000 \\
Total de asociados & 310 & 450 & 292 \\
\% de mujeres & $94 \%$ & $87 \%$ & $95 \%$ \\
\hline
\end{tabular}

FUENTE: Elaboración propia con base en datos suministrados por las cooperativas.

Las CTA estudiadas comparten la siguiente característica: fueron promovidas por líderes sociales, con el apoyo de entidades públicas y privadas, que encontraron en el cooperativismo una opción para superar las condiciones de pobreza de territorios rurales a través de la generación de fuentes de trabajo, especialmente para mujeres campesinas con bajo nivel de escolaridad. El estudio de estos casos es relevante no solo para el contexto colombiano, en el cual el fomento de las cooperativas

3.- Por acuerdos éticos de la investigación se omiten los nombres de las cooperativas estudiadas. 
resulta clave para lograr el desarrollo integral de los territorios rurales afectados por el conflicto armado, sino también para otros contextos en condiciones similares de conflicto o que pretendan estimular la generación de trabajo a través de CTA.

Los datos requeridos en el desarrollo de esta investigación fueron recolectados desde diferentes fuentes: asociados de las cooperativas, documentos e informes elaborados por cada cooperativa y las entidades que las agremian y vigilan. Para la recolección de la información se emplearon entrevistas semiestructuradas, talleres grupales y revisión bibliográfica. Las entrevistas y los talleres fueron grabados y sometidos a un proceso de transcripción para su análisis. La combinación de varias fuentes y técnicas de recolección de información contribuyó a disminuir los riesgos de no validez y parcialidad, a través de la triangulación.

Para seleccionar los asociados participantes se utilizó la estrategia de la cadena de informantes; asegurándose de incluir asociados con diferentes niveles de antigüedad y cargos desempeñados, con el fin de considerar diferentes perspectivas que reflejaran la diversidad de cada cooperativa. En total se realizaron 28 entrevistas individuales con una duración promedio de 34 minutos cada una 4 , tres (3) talleres grupales, uno en cada CTA seleccionada para el estudio, en promedio participaron 13 asociados en cada uno de los talleres, éstos tuvieron una duración aproximada de 111 minutos. El objetivo del taller era validar en cada cooperativa la conceptualización de la gestión humana socialmente responsable, que se había construido fundamentada en las entrevistas y el análisis de documentos. Las intervenciones y las observaciones de los asociados que participaron en cada taller fueron analizadas, hubo consenso respecto a la adecuación del análisis a la realidad de cada cooperativa, algunos asociados complementaron la descripción de algunas prácticas, sin embargo éstas eran acordes con las dimensiones de las categorías previamente definidas en la investigación, por lo cual no fue necesario ajustar el modelo teórico. El taller permitió confirmar que se había llegado al nivel de saturación en la construcción de las categorías y realizar una revisión por parte de los participantes en la investigación, lo que Maxwell (1996) denomina: member check.

El método de la teoría fundamentada requiere desarrollar diferentes tipos de codificación: abierta, axial y selectiva. Se utiliza la metáfora de "conocer el bosque" para explicar en qué consiste cada tipo de codificación y el proceso de análisis de datos seguido en esta investigación. La ilustración 1 resume este proceso.

El proceso de "conocer el bosque" implicó varios retos: penetrar en el bosque, observar los árboles y "describir su variedad" -codificación abierta-. En la codificación de las entrevistas y los talleres grupales se realizó un análisis línea por línea examinando cada frase expresada por los asociados. Luego de realizar la codificación de las primeras entrevistas se construyó una tabla que sintetizaba los códigos con sus descripciones y relaciones, esto permitía continuar el proceso de manera uniforme.

4.- Diez entrevistas del caso 1, diez entrevistas del caso 2 y ocho entrevistas del caso 3. 


\section{llustración 1. El proceso de análisis de datos y la metáfora de "conocer el bosque"}

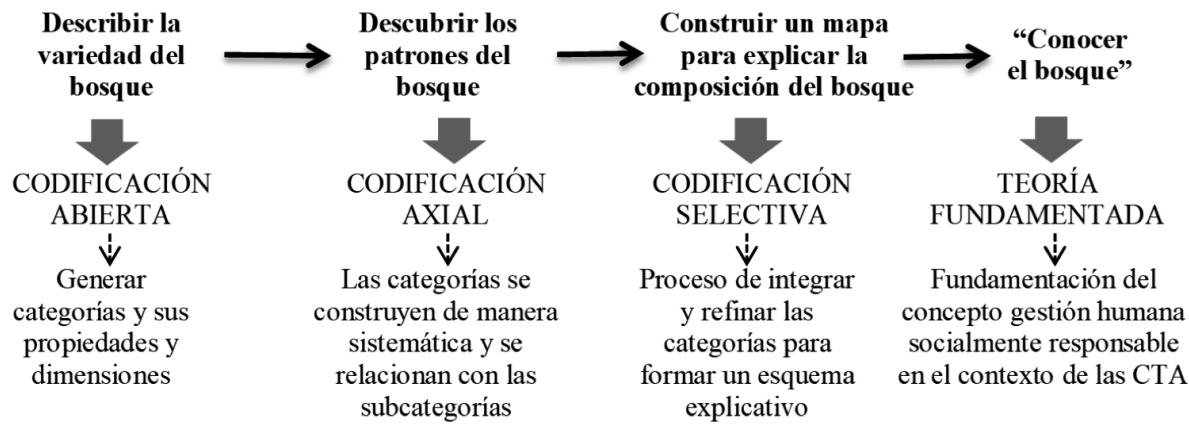

FUENTE: Elaboración propia con base en Strauss y Corbin (2002).

Posteriormente, los códigos fueron agrupados entre sí para formar las categorías. Las prácticas de información, formación, participación, igualdad de oportunidades se agruparon en la categoría "prácticas de empoderamiento de los asociados", el nombre de esta categoría surgió al analizar los datos y encontrar que los asociados usaban recurrentemente las palabras "tener", "poder", "derecho a", "saber", "tomar decisiones", al referirse a esas prácticas, un ejemplo, es el siguiente testimonio: "todo asociado tiene voz y voto, de hecho las decisiones de reglamentos, de estatutos, de todo eso se toma con la Asamblea, y es allá donde toda la gente va a expresar su opinión y tienen derecho a votar, a elegir".

Al indagar sobre las prácticas de formación, participación, condiciones de trabajo, salud y seguridad laboral, balance trabajo-familia, los asociados entrevistados utilizaron frecuentemente las palabras: "oportunidades", "posibilidades", "beneficios", "progreso", "mejoramiento", "aportes", para describir sus experiencias en la cooperativa, así lo expresa una asociada: "[la cooperativa] le brinda a uno todas las oportunidades y todas las prestaciones (...) gracias a ella tengo mi casita, puedo educar a mis hijos, colaborarle a mi familia (...) Me siento muy contenta y orgullosa de trabajar allá". Al profundizar en el análisis se encontró que esas oportunidades giraban en torno a tres aspectos: los laborales, los económicos y los sociales, que se constituían en oportunidades para el mejoramiento de sus vidas, razón por la cual se agruparon en la categoría "prácticas de bienestar de los asociados". Finalmente, el nombre de la categoría "prácticas de proyección a la comunidad", fue in vivo, es decir, tomado textualmente de la expresión de algunos asociados que se referían a cómo las cooperativas expresaban su interés por la comunidad, a través de la información y la formación.

El segundo reto era identificar conjuntos de árboles con características similares para "descubrir los patrones del bosque" -codificación axial-. En este punto del proceso de investigación, los "árbo- 
les del bosque" ya se podían agrupar en tres conjuntos de prácticas. Sin embargo, aún quedaban algunos árboles por agrupar, códigos como "solidaridad", "agencia", "métodos de trabajo", entre otros, no lograban identificarse con uno de esos conjuntos iniciales. Al profundizar en la codificación axial, se descubrió que ellos hacían parte de otros conjuntos de árboles: "las condiciones" y las "capacidades", éstas se constituyen en las subcategorías, es decir, aquellas que explican por qué, cómo y con qué consecuencias se realizan las prácticas de GH en las cooperativas estudiadas.

El reto final era construir un mapa para "explicar la composición del bosque" -codificación selectiva-. Este proceso implicó revisar cada categoría, verificar que éstas tuvieran densidad, que estaban detalladas todas sus propiedades y dimensiones, que estaban interrelacionadas y que se había alcanzado el nivel de saturación porque las entrevistas y los talleres no arrojaban datos nuevos. Un asunto clave en este proceso fue la construcción de un esquema que sintetizaba las relaciones entre todas las categorías surgidas del análisis, este esquema se presenta en la llustración 5. Como la recolección y el análisis de los datos se realizó durante 19 meses y el nombre de las propiedades y las dimensiones de cada categoría se iban transformando a medida que avanzaba el análisis, se decidió volver a codificar nuevamente todas las entrevistas con los códigos actualizados y realizar los talleres grupales para validar la construcción teórica. Al finalizar este proceso se logró "conocer el bosque", es decir, fundamentar el concepto gestión humana socialmente responsable en el contexto de las CTA. El análisis fue realizado con la ayuda del software Atlas.Ti versión 7.

\section{Resultados: gestión humana socialmente responsable en CTA}

Las prácticas de GH inicialmente seleccionadas, posteriormente se agruparon, con base en el análisis de los datos de los casos estudiados, con las denominaciones de: prácticas de empoderamiento de los asociados, prácticas de bienestar de los asociados y prácticas de proyección a la comunidad, que corresponden a las categorías sobre las cuales se construye, en esta investigación, el concepto gestión humana socialmente responsable. A continuación se explican cada una de estas prácticas.

\subsection{Prácticas de empoderamiento de los asociados y capacidad de agencia}

Las prácticas de empoderamiento están orientadas a desarrollar la capacidad de agencia de los asociados para que puedan participar con autonomía y responsabilidad como trabajadores, propietarios y gestores de la cooperativa. El empoderamiento requiere el reconocimiento de igualdad de oportunidades a todos los asociados para el acceso a la información, la formación y la participación, lo cual implica considerar las condiciones que afectan sus oportunidades. En el Anexo A se presentan testimonios sobre estas prácticas. La siguiente ilustración esquematiza las prácticas de empoderamiento. 


\section{llustración 2. Prácticas de empoderamiento de los asociados}

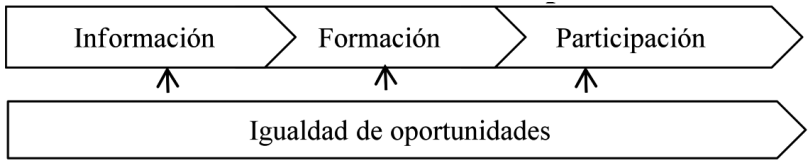

FUENTE: Elaboración propia.

\author{
Finalidad \\ $\checkmark$ \\ Desarrollar la \\ capacidad de agencia
}

\section{Información}

Es una práctica orientada a entregar a los asociados datos contextualizados acerca de la cooperativa y de aquellos asuntos del entorno que inciden en ésta, para que puedan tomar decisiones como trabajadores, propietarios y gestores de la cooperativa. A través del análisis de los datos se logró comprender que el contenido, la frecuencia y el acceso a la información son las dimensiones que caracterizan esta práctica.

Las cooperativas son organizaciones con una doble perspectiva: la de asociación y la de empresa. Desde la primera perspectiva se enfatiza en la asociación de personas que buscan satisfacer conjuntamente sus necesidades, con base en los principios cooperativos que le otorgan identidad. Desde la perspectiva empresarial, se reconoce que el logro de los objetivos comunes de los asociados se realiza a través de la ejecución de una actividad económica organizada. El contenido de la información dirigida a los asociados es integral cuando aborda ambas perspectivas de la cooperativa y es focalizado cuando hace énfasis en una de ellas.

La frecuencia de la información indica la periodicidad con la cual ésta es divulgada, es permanente cuando periódicamente -mensual, trimestral, etc.- los asociados reciben información acerca de la cooperativa y, es temporal cuando éstos son informados en las reuniones ordinarias 0 extraordinarias de la asamblea general que se realizan anualmente. El acceso se refiere a la posibilidad que tienen los asociados de estar informados y puede ser abierto o restringido. Es abierto cuando la cooperativa utiliza los mecanismos necesarios para llevar la información a todos los asociados. Es restringido cuando existen condiciones que limitan la posibilidad de los asociados de estar informados, tales como el cargo que desempeñan, la frecuencia con la cual son informados, su nivel de formación.

En las cooperativas estudiadas, los dirigentes y quienes participan en los órganos de dirección y de control, son los principales interlocutores para presentar las propuestas e inquietudes de los asociados en las instancias de decisión, y son los encargados de comunicar la información de los asuntos y decisiones que emiten tales órganos. Esta situación tiene varias implicaciones. Desde el punto de vista de las relaciones que establecen los asociados con sus dirigentes, la actitud de éstos es 
fundamental para generar compromiso o indiferencia por parte de los asociados con los asuntos de la cooperativa. Si el dirigente no comprende la importancia de las prácticas de información, puede asumir el ejercicio de informar como un asunto de cumplimiento, así lo expresa un dirigente cooperativo: "no estamos haciendo bien el proceso de informar a los asociados, o sea, le hemos perdido como la mística, lo estamos haciendo, en muchos casos, como una obligación, como por cumplir". Por otra parte, la eficacia de estas prácticas depende de las habilidades de los dirigentes para comunicar la información, las carencias o dificultades de éstos pueden afectar la calidad y el contenido de la información que llega a los asociados. Entonces, para que las prácticas de información logren su cometido, se hacen indispensables las prácticas de formación, que cualifiquen a los dirigentes en el ejercicio de informar y a los asociados para comprender la información.

\section{Formación}

Prácticas a través de las cuales los asociados desarrollan capacidades para la participación en la cooperativa como trabajadores, propietarios y gestores de la misma, logran ser y hacer lo que consideran valioso para sus vidas y los habilita para tomar decisiones con autonomía y responsabilidad. Estas prácticas incluyen la formación general, relacionada con la escolaridad básica -primaria y bachiIlerato-, los estudios de pregrado y posgrado y otros aspectos complementarios -cuidado de la salud, cultura, arte-, que mejoran la empleabilidad y el bienestar de los asociados, así como la formación para el trabajo que desarrolla habilidades para ejercer un oficio en la cooperativa; al igual que la educación cooperativa, todas éstas necesarias para ejercer los derechos y deberes de los asociados.

Las prácticas de formación poseen las mismas dimensiones que la información, es decir, la variación dimensional de dichas prácticas se comprende en cuanto al contenido, la frecuencia y el acceso. El contenido puede ser integral o focalizado, es integral cuando la cooperativa ofrece oportunidades de formación en todos los aspectos -formación general, para el trabajo y cooperativa- y es focalizado cuando hace énfasis en algunos de ellos. La frecuencia indica la periodicidad con la cual la cooperativa ofrece oportunidades de formación a los asociados. Es permanente cuando éstas se ofrecen continuamente y es temporal cuando las prácticas se ofrecen sólo por un tiempo o de forma esporádica. Según las posibilidades de acceso, la formación puede ser abierta o restringida. Es abierta cuando todos los asociados tienen oportunidades para acceder a las prácticas de formación y es restringida cuando se establecen criterios para permitir el acceso a la formación o existen condiciones como las responsabilidades familiares, la oferta educativa, los turnos laborales, que obstaculizan el acceso a la formación.

En dos CTA estudiadas, el contenido de las prácticas de formación ha estado focalizado en la formación para el trabajo y en aspectos artísticos; la educación cooperativa ha tenido una frecuencia temporal, limitada a los cursos de inducción para la vinculación de los asociados, esta situación puede conducir a que éstos entiendan la educación cooperativa como un requisito legal, obsérvese el testimonio de una asociada: "yo diría que aquí nos falta un poquito más el tema de formación porque a nosotros nos dan un curso de cooperativismo, de relleno, donde la gente recibe 20 horas en el pen- 
sum, pero si eso lo hiciéramos más a consciencia y la cooperativa dijera venga vamos a coger a los que ya hicieron cooperativismo y expliquémosle (...), pero ya no desde la teoría sino desde la práctica y la vivencia". Es decir, la frecuencia temporal con la que se realizan las prácticas de formación en cooperativismo, tal como se evidencia en el testimonio citado, en ocasiones se asume como un requisito, "curso de relleno", que hay que cumplir para poder ser asociado, sin tener consciencia de los derechos y las responsabilidades que se asumen.

\section{Participación}

En esta investigación, la participación se define como una práctica que tiene como propósito la implicación de los asociados en los aspectos económicos - participación económica- y en la gestión de la cooperativa -participación en la gestión-, éstas son las dos dimensiones de la participación. La participación económica tiene como finalidad la vinculación de los asociados en la conformación del capital cooperativo, a través de sus aportes y la participación en los resultados -excedentes o pérdidas-, que incluye la compensación que se recibe por el trabajo y las prestaciones que otorga la cooperativa en dinero o en servicios, más allá de los mínimos exigidos por la normatividad.

Los asociados tienen el deber y el derecho de participar en la gestión de la cooperativa; a través de estas prácticas se promueve la elección democrática y la designación de los asociados en los órganos de dirección y de control. Así se materializa el principio de gestión democrática. Las decisiones pueden tomarse de forma autónoma, como expresión de la voluntad de los asociados, o puede ser dependiente de la injerencia de personas externas que actúan como asesores o empleados y hacen recomendaciones respecto a las decisiones que se deben tomar, así lo evidencia este testimonio: "a nosotros nos dejan opinar, [pero], como uno no sabe tanto de leyes, (...) le dice al promotor principal, explíquenos ese punto, él nos aconseja, nos dice: "yo les aconsejo que digan que si". En dos CTA estudiadas se encontró que existe dependencia de personas externas que influyen en las decisiones que toman los asociados, las carencias en la formación general por parte de éstos conllevan a esta dependencia y termina afectando la participación, porque los asociados se concentran en su trabajo -rol de trabajadores- $y$ descargan en esas personas las responsabilidades que les competen como propietarios y gestores.

\section{Igualdad de oportunidades}

En los estatutos de las CTA estudiadas es usual encontrar el concepto de "no discriminación", pero es necesario avanzar hacia la "igualdad de oportunidades". El primero enfatiza en la igualdad de deberes y derechos; mientras que la igualdad de oportunidades implica considerar las condiciones que pueden afectar las oportunidades de los asociados para ejercer sus deberes y sus derechos. El siguiente testimonio, sobre las prácticas de formación, es revelador de este aspecto: "Nosotros pensamos que el tiempo no alcanza, (...) a la gente se le dificulta el tiempo, entonces, sería pensar en el tiempo dentro de la jornada laboral, como una acción de mejora. Y, la mayoría de asociadas son madres solteras, cabeza de hogar, entonces, es más difícil. Hay personas a las que se les dificulta más, hay otros 
que no, entonces, es pensar también cómo sectorizar la población [asociados], porque es que el sector más vulnerable también tiene derecho a aprovechar esto". Aunque los asociados tienen el derecho de acceder a las prácticas de formación, información y participación, porque así está estipulado en los estatutos de las cooperativas estudiadas, no hay igualdad de oportunidades para todos, pues, éstos se enfrentan a diferentes condiciones que afectan sus oportunidades.

El aporte de esta investigación consiste en poner de manifiesto que es necesario considerar las condiciones que afectan las oportunidades de los asociados para acceder a las prácticas de GH que las CTA realizan; en el numeral 4.4 se explican esas condiciones.

\section{Capacidad de agencia}

La capacidad de agencia se define como las oportunidades que disponen los asociados para participar con autonomía y responsabilidad como trabajadores, propietarios y gestores de la cooperativa. Las oportunidades se refieren al conjunto de opciones de las cuales se puede elegir. La autonomía hace alusión a la posibilidad que tienen los asociados de definir sus propias reglas -cómo opera la cooperativa-, de actuar con independencia. La responsabilidad significa asumir los deberes y los derechos que se derivan de la condición de asociados. Para ilustrar esta capacidad, resulta pertinente el siguiente testimonio: "Lo más valioso para mí, en primer lugar por mi experiencia ha sido la formación. Y segundo, el poder uno abiertamente decir las cosas, (...) uno aquí puede decidir, puede aportar (...) Cuando uno sabe aprovechar ese derecho que tiene de ser dueño, de ser gestor eso es muy valioso (...). A pesar de que hay otras personas que saben mucho más que uno, por el conocimiento y todo, uno está en el mismo nivel para aportar y para hacer valer sus derechos". En el testimonio citado se pueden identificar algunas de las dimensiones que caracterizan las prácticas de empoderamiento, se menciona el tema de la formación, la participación y la igualdad de oportunidades para decidir y para hacer valer sus derechos.

Testimonios similares se encontraron en las tres CTA estudiadas, sin embargo, algunos entrevistados también reconocen que no todos los asociados han logrado desarrollar la capacidad de agencia, han sido empoderados como trabajadores, pero no han asumido el rol de propietarios y gestores, así se expresa una asociada: "la gente [asociados] siente que viene simplemente a recibir un sueldo y que esto es una empresa capitalista, no hay el sentimiento de la copropiedad de la cooperativa,(...) es la misma incomprensión de lo que es ser asociado". Para hacer frente a esta situación, las prácticas de formación cooperativa resultan fundamentales, pero como se explicó anteriormente, en dos de las CTA analizadas éstas han tenido un carácter temporal.

\subsection{Prácticas de bienestar de los asociados y capacidad de bienestar}

Las prácticas de bienestar están orientadas a proporcionar a los asociados oportunidades laborales, económicas y sociales que contribuyan al desarrollo de su capacidad de bienestar, para ser y 
hacer lo que ellos consideran valioso para sus vidas, a través de la formación, la participación, las condiciones de trabajo, salud y seguridad y el balance trabajo-familia. En el Anexo B se presentan testimonios sobre estas prácticas. La siguiente ilustración presenta una síntesis de estas prácticas.

\section{Ilustración 3. Prácticas de bienestar de los asociados}

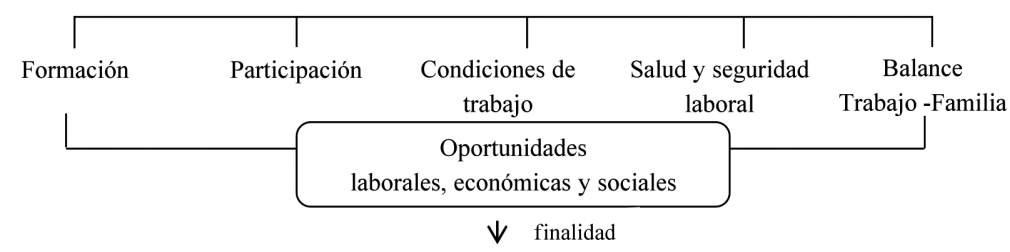

Desarrollar la capacidad de bienestar

FUENTE: Elaboración propia.

\section{Oportunidades laborales}

Las oportunidades laborales se refieren a las opciones que ofrecen las cooperativas de ejercer un trabajo, a través de las cuales los asociados disponen de oportunidades para ser y hacer lo que consideran valioso para sus vidas. Los resultados de esta investigación indican que la ubicación, la estabilidad y las condiciones de trabajo son las dimensiones que permiten valorar las oportunidades laborales que ofrecen las CTA estudiadas.

En cuanto a la ubicación de las cooperativas, ésta puede variar en un rango dimensional de cerca o lejos de la familia. La facilidad de tener una oportunidad de trabajo cerca del lugar de residencia de la familia contribuye al bienestar de los asociados. Esta es una dimensión especialmente valorada en los territorios rurales, así lo expresa una asociada: "Es muy agradable uno vivir en un municipio donde uno tenga su familia, tenga la parte económica y la tranquilidad porque se vive bien, entonces, por eso yo vivo muy agradecida con la cooperativa: porque estoy cerca de mi familia no me he tenido que ir a una ciudad".

La estabilidad laboral, entendida como la permanencia del vínculo asociativo entre la cooperativa y los asociados varía en un rango dimensional de permanente o temporal. Es permanente cuando la cooperativa procura preservar los puestos de trabajo de sus asociados. Es temporal cuando la vinculación y desvinculación de los asociados varía considerablemente según el flujo de producción. La permanencia del vínculo asociativo es una dimensión valorada positivamente por los asociados entrevistados.

Las condiciones de trabajo se refieren a la infraestructura productiva, relacionada con la calidad y la disposición de la maquinaria, las instalaciones; las compensaciones y las condiciones de salud 
y de seguridad laboral, más allá de los mínimos exigidos por la normatividad. Esta dimensión cobra mayor significación en el caso de las CTA colombianas, por la proliferación de pseudocooperativas que precarizaron las condiciones laborales. En los tres casos estudiados las condiciones laborales son acordes con la normatividad y contemplan beneficios adicionales.

\section{Oportunidades económicas}

Las oportunidades económicas representan las facilidades de acceso a los recursos económicos, que les permiten a los asociados disponer de recursos para producir, adquirir, consumir y así lograr funcionamientos valiosos. Esta disponibilidad de recursos puede variar en un rango dimensional de suficientes o precarios, dependiendo de algunas condiciones de los asociados -estado de salud, responsabilidades familiares-, de la cooperativa -prosperidad o crisis- 0 del entorno donde se ubican estas organizaciones. Así se expresa una asociada: "Usted puede estar aquí con todas las garantías y todas las condiciones pero sabe que le llega una quincena y ya la tiene comprometida, que no le va a alcanzar, que su mamá o sus hijos tienen problemas de salud". Al evaluar las oportunidades económicas que ofrecen las CTA a sus asociados, la gestión humana socialmente responsable debe considerar la diversidad de condiciones que inciden en las oportunidades de éstos, y que hacen que los recursos sean suficientes para algunos de ellos y precarios para otros, generando consecuencias en su capacidad de bienestar.

\section{Oportunidades sociales}

Las oportunidades sociales están representadas en las prácticas de formación y los servicios sociales que ofrecen las cooperativas a los asociados, que contribuyen a desarrollar su capacidad de bienestar, y les facilita lograr funcionamientos valiosos, según los intereses y las preferencias de los asociados. Las prácticas de formación varían en un rango dimensional según el contenido, la frecuencia y el acceso, según se explicó anteriormente.

En cuanto a los servicios sociales, estos incluyen los servicios de salud, recreación y asistencia en calamidades. Estos servicios sociales varían, según la disponibilidad, en un rango dimensional de suficientes o precarios, por condiciones del entorno externo como la ubicación o la situación económica de las cooperativas.

En síntesis, en las tres cooperativas estudiadas los asociados están afiliados al sistema de seguridad social, esto les permite acceder a servicios sociales de salud y otros servicios de prevención. Del mismo modo, se encuentran testimonios sobre el acompañamiento y el apoyo de las cooperativas en las situaciones de calamidad de los asociados, esto contribuye a desarrollar sus capacidades de bienestar y de solidaridad, tal como se explicará más adelante. 


\section{Capacidad de bienestar}

La capacidad de bienestar se refiere a las oportunidades laborales, económicas y sociales que ofrecen las cooperativas a los asociados, para que puedan lograr funcionamientos valiosos, como tener un trabajo, disponer de recursos para acceder a la nutrición, la salud, la seguridad, la vivienda, la recreación, el vestido, participar en la formación, entre otros, de acuerdo con los intereses de los asociados. En los casos estudiados, los entrevistados coinciden en señalar que las cooperativas han contribuido a desarrollar su capacidad de bienestar, así lo expresa una asociada: "[La cooperativa] me ha aportado beneficio económico, tranquilidad, estabilidad y una sostenibilidad como familia, como grupo de la sociedad, (...) tiene uno muchas opciones para ir mejorando la calidad de vida".

En este testimonio se pueden identificar las dimensiones que caracterizan la capacidad de bienestar de los asociados, aunque no se menciona explícitamente las oportunidades laborales, se deduce que es a partir de éstas que los asociados pueden disponer de oportunidades económicas y sociales. Las prácticas de bienestar no sólo benefician a los asociados, también se proyectan a su familia, como beneficiaria de algunas de estas prácticas.

\subsection{Prácticas de proyección a la comunidad y capacidad de solidaridad}

Las prácticas de proyección a la comunidad están orientadas a desarrollar la capacidad de solidaridad de los asociados, para fortalecer el sentido de la responsabilidad y de la ayuda entre los asociados y las comunidades a las que éstos pertenecen, a través de las prácticas de información y de formación dirigidas a la comunidad, así se presenta en la siguiente ilustración.

\section{llustración 4. Prácticas de proyección a la comunidad}

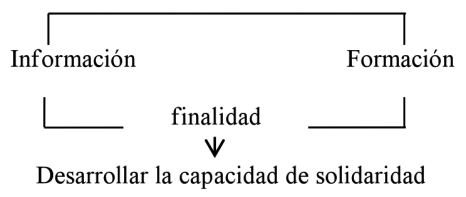

FUENTE: Elaboración propia.

\section{Información}

La información es una forma básica de proyección a la comunidad. Una comprensión más detallada acerca de las prácticas de información dirigidas a la comunidad externa es posible cuando se estudian sus dimensiones: el contenido, la frecuencia y el acceso, como se explicó anteriormente. 
Las prácticas de información como forma de proyección a la comunidad son de doble dirección, se requiere que la comunidad se entere de lo que sucede en las cooperativas, pero, al mismo tiempo, se necesita que las cooperativas conozcan las problemáticas o necesidades de la comunidad, como lo señala una asociada al referirse a los aspectos que su cooperativa debe mejorar: "una de las acciones (de mejoramiento) es conocer la comunidad y sus problemas, para anticiparse y poder apoyar aquello en lo que realmente sí podemos, por ejemplo, en información o investigación, que le permita a uno actuar bajo ciertos parámetros". Esto es esencial para desarrollar la capacidad de solidaridad de los asociados y dar cumplimiento al principio cooperativo de interés por la comunidad.

Las prácticas de información en dos de las cooperativas estudiadas, se limitan a dar cumplimiento a los requerimientos legales, no cuentan con una página de internet $u$ otros medios para informar a la comunidad; el contenido de la información está focalizado en aspectos financieros, la frecuencia es temporal y el acceso es restringido.

\section{Formación}

Las cooperativas se proyectan a la comunidad a través de prácticas de formación, realizadas directamente por las CTA o a través de becas, donación de aportes, equipos, útiles escolares, cesión de espacios. Estas prácticas varían en un rango dimensional según el contenido, la frecuencia y el acceso, como se explicó anteriormente. En el Anexo $\mathrm{C}$ se presentan testimonios sobre estas prácticas.

Las tres cooperativas estudiadas tienen centros de formación en confección industrial, a través de los cuales capacitan, de manera gratuita, a sus asociados y a las personas de la comunidad. Esto ha estimulado el surgimiento de talleres familiares y el asentamiento de otras empresas dedicadas a esta actividad, de este modo contribuyen con el fortalecimiento de la confección como una actividad importante para la economía de los municipios donde se encuentran ubicadas, así se puede apreciar en el siguiente testimonio: "Nosotros alguna vez hicimos la cuenta y llevábamos 1120 personas formadas, o sea, en el Municipio ha sido tanto éxito la confección (...) porque hay mucha gente formada, que conoce eso". Estas prácticas son de acceso abierto, su contenido es integral, incluye formación laboral y cooperativa y su frecuencia es permanente. Adicionalmente, en dos de las cooperativas estudiadas se cuenta con centros de formación musical, los cuales imparten educación gratuita para la comunidad, estas prácticas son de acceso abierto, su contenido es focalizado y su frecuencia es permanente.

\section{Capacidad de solidaridad}

La capacidad de solidaridad se refiere a las oportunidades que ofrecen las cooperativas para fortalecer el sentido de la responsabilidad y de la ayuda entre los asociados, como miembros de la cooperativa y de una comunidad. Ésta se ejerce en dos dimensiones, una personal y la otra laboral. En la dimensión personal, la capacidad de solidaridad se expresa en el acto de sentir compasión por el otro, de ayudarlo en sus necesidades. En la dimensión laboral, la capacidad de solidaridad se ejerce cuando 
el asociado reconoce la responsabilidad colectiva que asume como miembro de la cooperativa, pues, sus acciones u omisiones en el ejercicio de sus roles afecta positiva o negativamente a los demás asociados y a la cooperativa en su conjunto. Este testimonio resulta pertinente para comprender esta capacidad: "uno piensa la solidaridad como concepto y como acción, digamos que una cooperativa no se concibe sin ésta, porque ésta es como el ADN, pues, como que debemos tenerlo ahí, como por la sangre. No solo cuando hay ciertas complicaciones externas se necesita solidaridad, también en el día a día del trabajo".

Los hallazgos de esta investigación indican que las deficiencias en el desarrollo de la capacidad de solidaridad en su dimensión laboral, deterioran el escenario para el ejercicio de la capacidad de agencia, así lo expresa una entrevistada: "aquel que quiere participar [en los órganos de dirección] no encuentra un apoyo del grupo, o sea, prácticamente, primero lo monta [elige] y después le da palo [crítica] (...) no hay solidaridad en ese aspecto (...) somos muy detractores, o sea, nos gusta es mirar lo malo y a veces no ver lo bueno y que la persona también está haciendo un esfuerzo de poner la cara por todos". Es difícil ejercer con autonomía y responsabilidad los roles del asociado, cuando no se cuenta con la ayuda del grupo.

\subsection{Condiciones que afectan el cumplimiento de los principios cooperativos}

En esta investigación se identificaron algunas condiciones que afectan el cumplimiento de los principios cooperativos y el desarrollo de las capacidades de los asociados. Estas condiciones pueden ser de carácter personal de los asociados; otras surgen en la dinámica misma de las organizaciones cooperativas, otras provienen del entorno externo en el que éstas operan. En el Anexo D se presentan algunos testimonios sobre estas condiciones.

\section{Condiciones personales}

Éstas incluyen el nivel de formación, las responsabilidades familiares y el estado de salud del asociado o su familia. El nivel de formación de los asociados, se refiere al grado de escolaridad alcanzado por éstos, un bajo nivel de escolaridad restringe las oportunidades de participación, y genera dificultades para acceder a la información.

En algunas ocasiones la participación en los órganos de dirección y de control requiere disponer de tiempo adicional a la jornada laboral para asistir a reuniones y cumplir con responsabilidades propias de esos cargos. Esto puede generar un detrimento en el tiempo que se dedica a la familia o a los compromisos personales, lo cual constituye un obstáculo para la participación, en especial de las mujeres asociadas. El estado de salud del asociado y su familia también puede afectar la capacidad de bienestar de los asociados, dado que, puede llegar a limitar sus oportunidades laborales -por enfermedady sus oportunidades económicas -una parte de los recursos se dedican a la adquisición de medicamentos, entre otros-. 


\section{Condiciones organizacionales}

Estas condiciones incluyen los métodos de trabajo, las relaciones de los asociados y sus dirigentes, la intervención de personas externas en las decisiones y la situación económica de las cooperativas. Los métodos de trabajo, se refiere a las disposiciones para organizar el trabajo, como por ejemplo, la asignación de los turnos laborales; esta asignación puede favorecer o generar restricciones para algunos asociados que desean participar en prácticas de formación.

La relación entre los asociados y sus dirigentes es una condición que afecta la gestión democrática. Los principios cooperativos constituyen el marco de actuación que regula esta relación, cuando existen incomprensiones o incumplimientos en el ejercicio de estos principios, se generan consecuencias en el empoderamiento de los asociados.

La intervención de personas externas, que actúan como asesores, en las decisiones de la cooperativa, es una condición organizacional que puede originarse en respuesta a una condición personal de los asociados, relacionada con el bajo nivel de formación, como sucede en dos de los casos estudiados. En los primeros años de las cooperativas, esta intervención puede interpretarse como una respuesta estratégica a esa condición, sin embargo, la permanencia en el tiempo de esta intervención puede generar una relación de dependencia. Finalmente, la situación económica de la cooperativa -prosperidad o crisis- afecta los recursos disponibles para invertir en las prácticas de gestión humana socialmente responsable.

\section{Condiciones del entorno externo}

La normatividad es una condición externa que afecta las prácticas de gestión humana de las cooperativas, ésta define el modo en que se deben destinar los excedentes, las cuantías y los beneficiarios de algunas prácticas, los órganos de dirección y de control que deben conformar.

Por otra parte, la ubicación y la disponibilidad de recursos en el lugar donde operan las cooperativas puede favorecer u obstaculizar el ejercicio de algunas prácticas. En lugares donde la oferta laboral es muy escasa, algunas personas se vinculan a las cooperativas por la necesidad de trabajo sin tener la convicción de querer ser asociados. También se pueden generar restricciones por la escasez de la oferta educativa en los sectores donde se ubican las cooperativas, como sucede en uno de los casos estudiados; esto dificulta la ejecución de las prácticas de formación.

\subsection{Gestión humana socialmente responsable}

Con fundamento en los hallazgos de esta investigación, la gestión humana socialmente responsable en las CTA se define como un conjunto de prácticas, fundamentadas en los principios coope-

rativos, que están orientadas a desarrollar las capacidades de agencia, de bienestar y de solidaridad 
de los asociados, a través de la información, la formación, la participación, las condiciones de trabajo, la salud y la seguridad laboral, la igualdad de oportunidades y el balance trabajo-familia, para empoderarlos como trabajadores, propietarios y gestores de la cooperativa; proporcionando oportunidades laborales, económicas y sociales que contribuyan a su bienestar y les permita ser y hacer lo que consideran valioso para sus vidas; y de proyección a la comunidad a través de la información y la formación. Para lograr este propósito es necesario tener en cuenta las condiciones personales, organizacionales y del entorno externo que afectan estas prácticas, el cumplimiento de los principios cooperativos y el desarrollo de las capacidades de los asociados. La siguiente ilustración resume las categorías y las condiciones que constituyen este concepto.

\section{llustración 5. Gestión humana socialmente responsable en CTA}

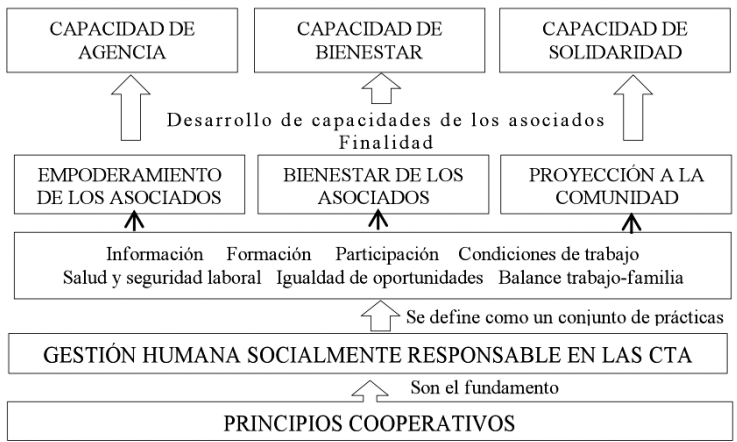

FUENTE: Elaboración propia.

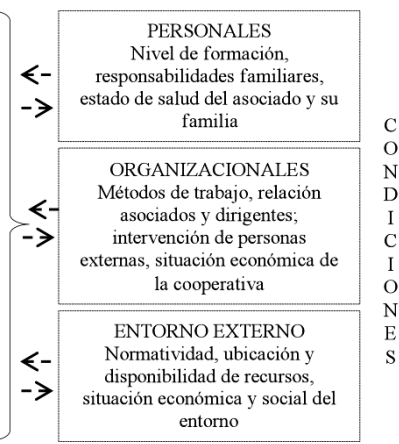

Las dinámicas organizacionales que se tejen en torno a la gestión humana socialmente responsable en las CTA y la construcción teórica que se propone en esta investigación para explicarla, reconoce la complejidad de las relaciones que se establecen entre sus componentes, a saber: las prácticas, las capacidades y las condiciones; ella da cuenta de interacciones de mutua influencia. Las prácticas de empoderamiento y de bienestar de los asociados y de proyección a la comunidad interactúan entre sí, una misma práctica -por ejemplo, la formación- puede contribuir a desarrollar diferentes capacidades. El reto de los asociados es tratar de reconocer y transformar las condiciones que inciden en esas prácticas, determinando cuáles de ellas favorecen u obstaculizan sus oportunidades para alcanzar el tipo de vida que valoran. 


\section{Conclusiones, limitaciones y futuras investigaciones}

La conceptualización de la gestión humana socialmente responsable que se propone en esta investigación, asume perspectivas diferentes a las que tradicionalmente se han utilizado en los campos de la RS y la GH. De un lado, se construye una perspectiva de integración (Voegtlin y Greenwood, 2016) basada en el enfoque de las capacidades y los principios cooperativos, para comprender cómo las prácticas de GH desarrollan diferentes capacidades de los asociados, mientras la literatura predominante asume una perspectiva instrumental. De otro lado, esta investigación se inscribe en un enfoque multinivel, tal como lo señalan Aguinis y Glavas (2012), porque permite comprender cómo los principios cooperativos -nivel institucional- se traducen en prácticas de GH -nivel organizacional- y explicar las implicaciones de esas prácticas en el desarrollo de las capacidades de los asociados -nivel individual-.

Algunos autores como Shen (2011), Shen y Zhu (2011), Celma et al. (2014), Barrena-Martínez et al. (2017), proponen conceptualizaciones sobre la gestión humana socialmente responsable. Los dos primeros enfatizan en multinacionales y grandes empresas de China, respectivamente, y consideran que ésta implica tener en cuenta los intereses de los grupos internos y externos de la organización con el fin de lograr la sostenibilidad en el largo plazo. Los dos últimos estudian empresas españolas, Celma et al. (2014) enfatizan en la calidad del trabajo, Barrena-Martínez et al. (2017) focalizan en el mejoramiento de las condiciones y desempeño global de los trabajadores. En esta investigación se enfatiza en un contexto diferente, CTA colombianas y en el desarrollo de las capacidades de los asociados como finalidad.

Esta investigación analiza algunas prácticas de GH que usualmente están incluidas en los principales estándares internacionales de RS como la información, la formación, la participación, las condiciones de trabajo, la salud y seguridad laboral, la igualdad de oportunidades y el balance trabajo-familia. No obstante, estas prácticas vistas desde la propuesta de esta investigación asumen un nuevo significado, como prácticas de empoderamiento, de bienestar y de proyección a la comunidad, pues atienden a una finalidad: el desarrollo de las capacidades de los asociados.

El concepto de empoderamiento se fundamenta en las investigaciones sobre la gestión participativa y la implicación de los trabajadores que enfatizan en compartir el poder y el control en la toma de decisiones y permitir el acceso a la información y la formación en todos los niveles de la jerarquía organizacional (Spreitzer, Kizilos y Nason, 1997). En esta investigación se encontró que las prácticas de información, formación, participación e igualdad de oportunidades contribuyen al empoderamiento y ayudan a desarrollar la capacidad de agencia de los asociados, es decir, fortalecen la autonomía y la responsabilidad de éstos y les permite tomar decisiones. 
Diversos autores han señalado la importancia de las prácticas de información y de formación para promover la participación democrática y el buen gobierno de las cooperativas (Eid y Martínez-Carrasco Pleite, 2014; Martínez Charterina, 2015). El aporte de esta investigación es explicar las dimensiones de las prácticas de información y de formación, para empoderar a los asociados y promover su participación, se requiere que el contenido de éstas sea integral, de frecuencia permanente y de acceso abierto para que todos los asociados pueden asumir con responsabilidad el rol de trabajadores, propietarios y gestores de la cooperativa.

En relación con la igualdad de oportunidades, autores como Cuadrado Serrán y Ciruela Lorenzo (2014), Martínez Charterina (2015), Santero Sánchez y Castro Núñez (2016) reconocen que las cooperativas favorecen la igualdad. Sin embargo, los estudios sobre igualdad de oportunidades generalmente focalizan en la perspectiva de género, dejando de lado otras condiciones que afectan las oportunidades de las personas independientemente de su género. Un aporte de esta investigación es explicar las condiciones personales, organizacionales y del entorno externo que afectan las oportunidades de los asociados para acceder a las prácticas de GH que las cooperativas realizan.

Las investigaciones de Barrena-Martínez et al. (2017), Barrena-Martínez, López-Fernández y Romero-Fernández (2018) señalan como aspecto clave de las prácticas de gestión humana socialmente responsable considerar las expectativas personales y profesionales de los trabajadores y mejorar el bienestar de éstos. Los hallazgos de esta investigación indican que las prácticas de formación, participación, condiciones de trabajo, salud y seguridad laboral y el balance trabajo-familia, están relacionadas con estos aspectos y contribuyen al desarrollo de la capacidad de bienestar de los asociados.

Autores, como Kooij, Guest, Clinton, Knight, Jansen y Dikkers (2013) estudian las prácticas de gestión humana que tienen incidencia en el bienestar de los trabajadores, éste se evalúa en términos de compromiso organizacional, la satisfacción laboral, la equidad organizacional y el desempeño del trabajo. Estos conceptos han sido los que tradicionalmente se analizan al estudiar los resultados de las prácticas de GH. En esta investigación se propone una concepción diferente para estudiar las prácticas de bienestar en términos de oportunidades laborales, económicas y sociales que se ofrecen a los asociados, lo cual implica un cambio de énfasis, de la perspectiva de la organización que ha sido dominante, a las oportunidades de las personas.

En la literatura sobre RS y GH algunos autores consideran que las prácticas de información (Lorenz, Gentile y Wehner, 2013) y de formación (Cooke y He, 2010) se constituyen en prácticas de proyección a la comunidad, situación que ha sido evidenciada en este estudio; estas prácticas contribuyen al desarrollo de la capacidad de solidaridad. Fernández (2012:140) considera que "la solidaridad (...) presupone una relación de pertenencia y, por lo mismo de asunción de una corresponsabilidad que vincula al individuo con el grupo social del que forma parte". Entonces, la capacidad de solidaridad implica el reconocimiento de los vínculos que unen a los asociados con unos colectivos de personas: la cooperativa y la comunidad y, como miembro de esos colectivos se asumen responsabilidades. 
Esta investigación propone la capacidad de solidaridad como una nueva dimensión a considerar en el enfoque de capacidades de Amartya Sen. El nivel de análisis que utiliza Sen es el individuo, éste desarrolla la capacidad de agencia cuando actúa de forma autónoma y asume la responsabilidad de sus decisiones. En esta investigación el nivel de análisis son los asociados que conforman las CTA, los hallazgos indican que la responsabilidad es un concepto que subyace a las capacidades de agencia y de solidaridad de los asociados de las CTA, pero opera en diferentes perspectivas: la individual -capacidad de agencia- y la colectiva -capacidad de solidaridad-. Aunque ambas capacidades son distintas existen relaciones entre éstas. Así, por ejemplo el desconocimiento de la responsabilidad colectiva y la falta de ayuda entre los asociados, desestimula la participación y el ejercicio de la capacidad de agencia.

Recientes estudios han analizado el potencial de las CTA para generar oportunidades laborales (Roelants et al., 2014). El aporte de esta investigación consiste en construir las dimensiones que permiten valorar las oportunidades laborales que ofrecen las cooperativas, a saber: la ubicación, la estabilidad laboral y las condiciones de trabajo. En la literatura sobre organizaciones de la economía social se ha dado mayor relevancia a la dimensión de estabilidad laboral (Martín y Lejarriaga, 2011; HerasSaizarbitoria, 2014); sin embargo, en esta investigación se ha encontrado que también la ubicación y las condiciones de trabajo resultan significativas para comprender la contribución de las cooperativas al bienestar de los asociados. La dimensión de ubicación cobra mayor relevancia en las áreas rurales con escasas fuentes de trabajo formal, como sucede en los casos estudiados. Las condiciones de trabajo resultan fundamentales de analizar cuando se estudian sectores proclives a la precarización laboral, como es el caso de la industria textil-confección y de las CTA que han sido utilizadas indebidamente en algunos países como Colombia, para flexibilizar y vulnerar los derechos laborales de las personas.

Los datos analizados permiten concluir que es posible llevar a cabo una gestión humana socialmente responsable en las CTA colombianas del sector textil-confección, cuando estas operan conforme a los principios cooperativos, éstos se constituyen en su fundamento y contribuyen al empoderamiento y bienestar de los asociados y a la proyección a la comunidad, desarrollando en los asociados la capacidad de agencia, bienestar y solidaridad. Así mismo, les permite cumplir con su propósito misional, a través de la generación de oportunidades laborales estables, reconociendo a los asociados condiciones laborales adicionales a las establecidas legalmente, aportando al bienestar de los asociados y sus familias y proyectándose a las comunidades a través de prácticas de información y de formación. Sin embargo, es necesario fortalecer las prácticas de información dirigidas a la comunidad, divulgar las prácticas de gestión humana socialmente responsables que las CTA realizan ayuda a visibilizar el aporte de estas organizaciones al desarrollo de las capacidades de las personas y las comunidades donde opera, contribuye a la compresión y a la reivindicación del cooperativismo de trabajo asociado como un modelo de emprendimiento legítimo.

Esta investigación tiene algunas limitaciones, en cuanto al contexto de estudio está focalizada en CTA colombianas del sector textil-confección, futuras investigaciones podrían replicar las proposi- 
ciones teóricas de esta investigación para estudiar CTA de otros sectores económicos, otros países y otros tipos de cooperativas o realizar estudios comparativos con otros tipos de empresas. De otro lado, la conceptualización de las capacidades agencia, bienestar y solidaridad de los asociados, ha sido concebida en términos teóricos, futuros estudios podrían operacionalizar y medir estas capacidades desde un punto de vista cuantitativo.

\section{Bibliografía}

ACI - ALIANZA COOPERATIVA INTERNACIONAL (1995): Declaración sobre Identidad Cooperativa, Manchester - Reino Unido: ACl.

AGUINIS, H. \& GLAVAS, A. (2012): "What We Know and Don't Know About Corporate Social Responsibility: A Review and Research Agenda", Journal of Management, 38(4), 932-968, doi: 10.1177/0149206311436079.

ÁLVAREZ, J.F. \& GARCÍA, A. (2010): "Las cooperativas de trabajo asociado y su instrumentalización en Colombia. Apuntes para repensar la incidencia de las políticas implementadas", Revista Idelcoop, 211, 28-44.

BÁEZ MELIÁN, J.M. (2011): "La participacion de los trabajadores en la empresa. El caso de Irlanda", CIRIEC-España, Revista de Economía Pública, Social y Cooperativa, 70, 127-148.

BARRENA-MARTÍNEZ, J., LÓPEZ-FERNÁNDEZ, M. \& ROMERO-FERNÁNDEZ, P.M. (2017): "Socially responsible human resource policies and practices: Academic and professional validation", European Research on Management and Business Economics, 23(1), 55-61, doi: http://dx.doi.org/10.1016/j.iedeen.2016.05.001

BARRENA-MARTÍNEZ, J., LÓPEZ-FERNÁNDEZ, M. \& ROMERO-FERNÁNDEZ, P.M. (2018): "Drivers and Barriers in Socially Responsible Human Resource Management", Sustainability, 10(1532), 114, doi: 10.3390/su10051532.

CALDERÓN, G., ÁLVAREZ, C.M. \& NARANJO, J.C. (2011): "Papel de gestión humana en el cumplimiento de la responsabilidad social empresarial", Estudios Gerenciales, 27(118), 163-188, doi: https://doi.org/10.1016/S0123-5923(11)70151-6.

CAMERON, J. \& EYESON, A. (2012): "Connecting Developments in Corporate Human Management Thinking to the Capability Approach as Used in International Development Research", Management Revue, 23(2), 173-190, doi: 10.1688/1861-9908:mrev:2012:02:Cameron. 
CELMA, D., MARTÍNEZ-GARCÍA, E. \& COENDERS, G. (2014): "Corporate Social Responsibility in Human Resource Management: An analysis of common practices and their determinants in Spain", Corporate Social Responsibility \& Environmental Management, 21(2), 82-99, doi: 10.1002/csr.1301.

CICOPA - COMITÉ EJECUTIVO DE LA ORGANIZACIÓN INTERNACIONAL DE COOPERATIVAS DE PRODUCCIÓN INDUSTRIAL, A.Y.D.S. (2005): Declaración Mundial sobre Cooperativismo de Trabajo Asociado, Oslo, CICOPA.

COMISIÓN EUROPEA (2011): Estrategia renovada de la UE para 2011-2014 sobre la responsabilidad social de las empresas, Bruselas, Comisión Europea.

CONFECÁMARAS (2016): "Nacimiento y supervivencia de las empresas en Colombia", Cuadernos de Análisis Económico, 11, 1-40.

CONFECÁMARAS (2017): "Determinantes de la supervivencia empresarial en Colombia", Cuadernos de Análisis Económico, 14, 1-28.

CONFECOOP (2017): Desempeño de las cooperativas en Colombia 2016, Bogotá, CONFECOOP.

COOKE, F.L. \& HE, Q. (2010): "Corporate social responsibility and HRM in China: a study of textile and apparel enterprises", Asia Pacific Business Review, 16(3), 355-376, doi: http://dx.doi.org/10.1080/13602380902965558.

CRACOGNA, D. (2015): "La legislación cooperativa latinoamericana en el marco del Plan para una Década Cooperativa de la Alianza Cooperativa Internacional" , REVESCO, Revista de estudios cooperativos, (117), 12-33, doi: http://dx.doi.org/10.5209/rev_REVE.2015.v117.48416.

CUADRADO, M. \& CIRUELA, A.M. (2014): "Las empresas de economía social como motor de desarrollo económico y social: análisis de su impacto socioeconómico en la región de Andalucía", REVESCO, Revista de estudios cooperativos, 115, 57-100, doi: http://dx.doi.org/10.5209/rev_REVE.2014.v115.45278

DANE (2017): Comunicado de prensa. Informes Especiales Mercado Laboral. Trimestre julio - septiembre 2017, Bogotá, DANE - Departamento Administrativo Nacional de Estadística.

DOWNS, Y. \& SWAILES, S. (2013): "A capability approach to organizational talent management. Human Resource Development International", 16(3), 267-281, doi: 10.1080/13678868.2013.782992.

EID, M. \& MARTíNEZ-CARRASCO PLEITE, F. (2014): "El año internacional del coooperativismo. Una aproximación a los desafíos del sector mediante el método Delphi", REVESCO, Revista de estudios cooperativos, 116, 103-129, doi: http://dx.doi.org/10.5209/rev_REVE.2014.v116.46568

FERNÁNDEZ, F. (2012): "La solidaridad como principio constitucional", UNED. Teoría y Realidad Constitucional, 30, 139-181. 
GADEA, E. (2012): "Delimitación del concepto de cooperativa: de los principios cooperativos a la responsabilidad social corporativa", CIRIEC-España, Revista Jurídica de Economía Social y Cooperativa, 23, 1-22.

GALLARDO-VÁSQUEZ, D., SÁNCHEZ-HERNÁNDEZ, M.I. \& CASTILLA-POLO, F. (2015): "Marco teórico y metodológico para la validación cualitativa de un modelo explicativo de la responsabilidad social en sociedades cooperativas", REVESCO, Revista de Estudios Cooperativos, 118, 86121, doi: http://dx.doi.org/10.5209/rev_REVE.2015.n118.49058.

GARCÍA, M., AZUERO, A.R. \& PELÁEZ, J.D. (2013): "Prácticas de Responsabilidad Social Empresarial desde las áreas funcionales de Gestión Humana: análisis de resultados en cuatro empresas del suroccidente colombiano", INNOVAR, Revista de ciencias administrativas y sociales, 23(49), 83-100.

GOND, J.-P., IGALENS, J., SWAEN, V. \& EL-AKREMI, A. (2011): "The human resources contribution to responsible leadership: an exploration of the CSR-HR interface", Journal of Business Ethics, 98, 115-132.

GUEST, D.E. (1987): "Human Resource Management and Industrial Relations", Journal of Management Studies, 24(5), 503-521.

HERAS-SAIZARBITORIA, I. (2014): "The ties that bind? Exploring the basic principles of worker-owned organizations in practice", Organization, 21(5), 645-665, doi: 10.1177/1350508414537623.

HYUNGSIK, E. (2017): Cooperatives and Employment. Second Global Report. Contribution of cooperatives to decent work in the changing world of work, Ginebra, CICOPA.

KOOIJ, D.T.A.M., GUEST, D.E., CLINTON, M., KNIGHT, T., JANSEN, P.G.W. \& DIKKERS, J.S.E. (2013): "How the impact of HR practices on employee well-being and performance changes with age", Human Resource Management Journal, 23(1), 18-35, doi: 10.1111/1748-8583.12000.

LORENZ, C., GENTILE, G.-C. \& WEHNER, T. (2013): "Exploring Corporate Community Engagement in Switzerland: Activities, Motivations, and Processes", Business \& Society, doi: 10.1177/0007650313482549.

MARTíN, S. \& LEJARRIAGA, G. (2011): "Las empresas de participación de trabajo asociado ante los desafíos del futuro en un contexto de crisis económica: propuestas de actuación", CIRIEC España, Revista de Economía Pública, Social y Cooperativa, 72, 239-261.

MARTÍNEZ CHARTERINA, A. (2015): "Las cooperativas y su acción sobre la sociedad", REVESCO, Revista de Estudios Cooperativos, 117, 34-49, doi: http://dx.doi.org/10.5209/rev_REVE.2015.v117.48144.

MAXWELL, J.A. (1996): Qualitative research design. An interactive approach, Thousand Oaks, Sage. 
MORGESON, F.P., AGUINIS, H., WALDMAN, D.A. \& SIEGEL, D.S. (2013): "Extending Corporate Social Responsibility Research to the Human Resource Management and Organizational Behavior Domains: A Look to the Future", Personnel Psychology, 66(4), 805-824, doi: 10.1111/peps. 12055.

MOZAS, A. \& PUENTES, R. (2010): "La Responsabilidad Social Corporativa y su paralelismo con las Sociedades Cooperativas", REVESCO, Revista de Estudios Cooperativos, 103, 75-100, doi: http://dx.doi.org/10.5209/REVE.19470.

RHODES, C. \& HARVEY, G. (2012): "Agonism and the Possibilities of Ethics for HRM", Journal of Business Ethics, 111(1), 49-59, doi: 10.1007/s10551-012-1441-0.

RODRÍGUEZ, A., MOYANO, J. \& JIMÉNEZ, J.J. (2015): "Estado actual de la investigación en Responsabilidad Social Corporativa a nivel organizativo: consensos y desafíos futuros", CIRIECEspaña, Revista de Economía Pública, Social y Cooperativa, 85, 1-39.

ROELANTS, B., HYUNGSIK, E. \& TERRASI, E. (2014): Cooperativas y empleo: un informe mundial, Ginebra, Desjardins.

SANTERO, R. \& CASTRO, B. (2016): "Análisis de las condiciones laborales en las entidades de la economía social en España desde una perspectiva de género", REVESCO, Revista de Estudios Cooperativos, 121, 228-255, doi: http://dx.doi.org/10.5209/rev_REVE.2016.v121.51309.

SEN, A. (1985): "Well-Being, Agency and Freedom: The Dewey Lectures 1984", The Journal of Philosophy, 82(4), 169-221, doi: 10.2307/2026184.

SEN, A. (1995): Nuevo examen de la desigualdad, Madrid, Alianza Editorial.

SEN, A. (2006): Desarrollo y Libertad, 8 a edición: Bogotá, Planeta.

SERVER, R. \& CAPÓ, J. (2011): "The interrelationship between the demands of Corporate Social Responsibility and co-operative principles and values", CIRIEC-España, Revista de Economía Pública, Social y Cooperativa, 73, 213-232.

SHEN, J. (2011): "Developing the concept of socially responsible international human resource management", International Journal of Human Resource Management, 22(6), 1351-1363, doi: 10.1080/09585192.2011.559104.

SHEN, J. \& ZHU, C.J. (2011): "Effects of socially responsible human resource management on employee organizational commitment", International Journal of Human Resource Management, 22(15), 3020-3035, doi: 10.1080/09585192.2011.599951.

SPREITZER, G.M., KIZILOS, M.A. \& NASON, S.W. (1997): "A Dimensional Analysis of the Relationship between Psychological Empowerment and Effectiveness Satisfaction, and Strain", Journal of Management, October 1, 23(5), 679-704, doi: 10.1177/014920639702300504.

STRAUSS, A. \& CORBIN, J. (2002): Bases de la investigación cualitativa. Técnicas y procedimientos para desarrollar la teoría fundamentada, Medellín, Editorial Universidad de Antioquia. 
SUPERINTENDENCIA DE LA ECONOMÍA SOLIDARIA (2017): Principales cuentas reportadas por entidades del Sector Solidario por tipo de entidad. Años 2002-2016, Bogotá, Supersolidaria.

SUPERINTENDENCIA DE SOCIEDADES (2015): Desempeño del sector textil-confección 2012-2014, Bogotá, Superintendencia de Sociedades.

TERRASI, E. \& HYUNGSIK, E. (2017): Cooperativas en la industria y los servicios. Informe mundial 2015-2016, Ginebra, CICOPA.

URQUIJO, M.J. (2008): La libertad como capacidad. El enfoque de las capacidades de Amartya Sen y sus implicaciones en la ética social y política, Santiago de Cali, Programa Editorial Universidad del Valle.

VOEGTLIN, C. \& GREENWOOD, M. (2016): "Corporate social responsibility and human resource management: A systematic review and conceptual analysis", Human Resource Management Review, 26(3), 181-197, doi: 10.1016/j.hrmr.2015.12.003.

YIN, R.K. (2003): Case Study Research. Design and Methods. Third edition, Thousand Oaks, Sage. 


\section{Anexo A. Testimonios sobre las prácticas de empoderamiento de los asociados}

\begin{tabular}{|c|c|c|}
\hline INFORMACIÓN & FORMACIÓN & PARTICIPACIÓN \\
\hline $\begin{array}{l}\text { Según el contenido: } \\
\text { Integral: "Nos informa de todo lo que } \\
\text { pasa en todas las plantas (sedes de la } \\
\text { cooperativa), cuánto hubo de ganancia, } \\
\text { de pérdidas, la gente que se vincula, la } \\
\text { que se retira" } \\
\text { Focalizado: "Con respecto al funciona- } \\
\text { miento de la cooperativa, ¿qué se le } \\
\text { dice a la gente?, todo lo que son los } \\
\text { estados de resultados, toda la informa- } \\
\text { ción contable está a disposición" }\end{array}$ & $\begin{array}{l}\text { Según el contenido: } \\
\text { Integral: "Se les ofrece un curso que } \\
\text { consta de dos partes: de la parte técnica } \\
\text { y de la parte social. La parte técnica es } \\
\text { enseñarles a las personas un oficio (...). } \\
\text { Pero más importante es la capacitación } \\
\text { social donde se da todo el tema de coo- } \\
\text { perativismo" } \\
\text { Focalizado: "Están constantemente } \\
\text { capacitándonos, (...) sobre todo lo que } \\
\text { hay que hacer en la cooperativa" }\end{array}$ & $\begin{array}{l}\text { Participación económica } \\
\text { En el capital: "cuando [las personas] las } \\
\text { asocian, uno debe tener un aporte (...), } \\
\text { desde ese momento son socios de la } \\
\text { cooperativa y participan en todo lo se } \\
\text { haga" } \\
\text { En los excedentes: "las utilidades se van } \\
\text { invirtiendo en la misma cooperativa (...) } \\
\text { Si fue un año bueno, entonces, tenemos } \\
\text { un aguinaldo mejor (...) Los excedentes } \\
\text { de la cooperativa va para cada uno de } \\
\text { los asociados en proporciones iguales" }\end{array}$ \\
\hline $\begin{array}{l}\text { Según la frecuencia: } \\
\text { Permanente: "Cada mes se hace una } \\
\text { reunión con todos los asociados y nos } \\
\text { dan a conocer cómo va la cooperativa" } \\
\text { Temporal: "En la asamblea que se hace } \\
\text { cada año (...) nos informan de todo, los } \\
\text { estados financieros" }\end{array}$ & $\begin{array}{l}\text { Según la frecuencia: } \\
\text { Permanente: "Todos los años dan cur- } \\
\text { sos, los cursos que la gente quiera y que } \\
\text { proponga se hacen". } \\
\text { Temporal: "A veces no se capacita sufi- } \\
\text { cientemente sobre cómo funcionan las } \\
\text { cooperativas, (...), sólo al principio en el } \\
\text { curso básico de economía solidaria" }\end{array}$ & $\begin{array}{l}\text { Participación en la gestión: } \\
\text { Autonomía: "Los asociados tenemos voz } \\
\text { y voto, porque uno es socio" } \\
\text { Dependencia: "El promotor principal es } \\
\text { el que hace la conexión, porque noso- } \\
\text { tros (asociados) no conocemos (...), él } \\
\text { tiene muy buenas conexiones, él conoce } \\
\text { mucho" }\end{array}$ \\
\hline $\begin{array}{l}\text { Según el acceso: } \\
\text { Restringido: "El Contador y el Revisor } \\
\text { Fiscal, cada mes, al Consejo de } \\
\text { Administración, le cuenta cuál fue el } \\
\text { resultado" }\end{array}$ & $\begin{array}{l}\text { Según el acceso: } \\
\text { Abierto: "les colaboro con el permiso } \\
\text { para que puedan estudiar (...), porque } \\
\text { eso es en beneficio de la cooperativa" } \\
\text { Restringido: "Si yo quiero hacer este } \\
\text { curso..., es muy limitado, (...) a uno no } \\
\text { le facilitan el tiempo por los dos turnos" }\end{array}$ & \\
\hline
\end{tabular}




\section{Anexo B. Testimonios sobre las prácticas de bienestar de los asociados}

\begin{tabular}{|l|l|l|}
\hline OPORTUNIDADES LABORALES & OPORTUNIDADES ECONÓMICAS & OPORTUNIDADES SOCIALES \\
\hline $\begin{array}{l}\text { Ubicación: "Yo vivo muy feliz en mi tra- } \\
\text { bajo y ojalá que este lugar no lo vayan } \\
\text { a cerrar porque muchas nos quedaría- } \\
\text { mos a la deriva, y nos tocaría alejarnos } \\
\text { de nuestras familias a conseguir trabajo } \\
\text { en otra ciudad" }\end{array}$ & $\begin{array}{l}\text { Disponibilidad de recursos } \\
\text { Suficientes: "Por el sueldito uno puede } \\
\text { comer mejor, vestir mejor, todo eso le } \\
\text { ayuda a uno como persona y se siente } \\
\text { bien" }\end{array}$ & $\begin{array}{l}\text { Formación: "[Continuamente] nos dan } \\
\text { capacitaciones, que son muy intere- } \\
\text { santes: de salud, de riesgos profesio- } \\
\text { nales, también de planificación familiar" }\end{array}$ \\
\hline $\begin{array}{l}\text { Estabilidad laboral: "En el sentido labo- } \\
\text { ral es excelente porque le dan a uno } \\
\text { estabilidad laboral (...) A pesar de que } \\
\text { la situación no siempre ha sido la mejor, } \\
\text { nos han sostenido a todos" }\end{array}$ & $\begin{array}{l}\text { Precarios: "Hay gente de acá [coopera- } \\
\text { tiva] que es muy pobre y tiene muchos } \\
\text { hijos, pues, porque es una realidad, } \\
\text { donde hay mucha diversidad, entonces, } \\
\text { encontrará gente que tiene [dificultades], } \\
\text { pero uno sabe que le está generando } \\
\text { trabajo" }\end{array}$ & $\begin{array}{l}\text { Servicios sociales: "El compromiso que } \\
\text { tiene la empresa cuando una persona } \\
\text { dificultad se le ayudada, no solo al aso- } \\
\text { ciado sino también al familiar" }\end{array}$ \\
\hline $\begin{array}{l}\text { Condiciones de trabajo: "Las instalacio- } \\
\text { nes cumplen con toda la normatividad } \\
\text { (...), aquí se trata de dar las máximas } \\
\text { condiciones para la gente, porque esto } \\
\text { es de nosotros y por eso velamos por- } \\
\text { que lo de nosotros sea lo mejor" }\end{array}$ & & \\
\hline
\end{tabular}

\section{Anexo C. Testimonios sobre las prácticas de proyección a la comunidad}

\begin{tabular}{|l|l|}
\hline INFORMACIÓN & FORMACIÓN \\
\hline "En la parte de información falta de divulgación a nivel externo & "La gente no tiene que pagar, (...), ponemos absolutamente \\
de lo que se hace (...), [es necesario] dar a conocer más los & todo, para que la gente salga capacitada y se certifican vein- \\
beneficios prestados a la comunidad por parte de la coope- & $\begin{array}{l}\text { ticinco (25) personas cada seis (6) meses (...). Eso es pro- } \\
\text { rativa" }\end{array}$ \\
& $\begin{array}{l}\text { yección a la comunidad, estamos aportando al sector } \\
\text { productivo y algunas personas para se puedan proyectar labo- } \\
\text { ralmente" }\end{array}$ \\
\hline
\end{tabular}




\section{Anexo D. Testimonios de las condiciones que afectan el cumplimiento de los principios cooperativos}

\begin{tabular}{|c|c|c|}
\hline PERSONALES & ORGANIZACIONALES & DEL ENTORNO EXTERNO \\
\hline $\begin{array}{l}\text { Nivel de escolaridad: "Todavía tenemos } \\
\text { en la cooperativa unas personas que a } \\
\text { veces no han alcanzado la primaria (...) } \\
\text { y eso les genera ciertas restricciones" }\end{array}$ & $\begin{array}{l}\text { Métodos de trabajo: "Para las operarias } \\
\text { es muy difícil [estudiar] por lo que tra- } \\
\text { bajan en una cadena y la una depende } \\
\text { de la otra, entonces, es más bien com- } \\
\text { plicado porque tiene que contar con que } \\
\text { una compañera le colabore con el turno" }\end{array}$ & $\begin{array}{l}\text { Normatividad } \\
\text { "Tenemos como un obstáculo la legisla- } \\
\text { ción y la normatividad, que nos regula } \\
\text { y nos obliga, a veces, a hacer cosas } \\
\text { para poder funcionar" }\end{array}$ \\
\hline $\begin{array}{l}\text { Responsabilidad familiar: "En el Consejo } \\
\text { [de Administración] no he participado, } \\
\text { me parece que es mucha responsabili- } \\
\text { dad, y a uno con los hijos, para estar en } \\
\text { reuniones y tener mucho tiempo dispo- } \\
\text { nible es difícil" }\end{array}$ & $\begin{array}{l}\text { Intervención de personas externas: } \\
\text { "Cuando la cooperativa se creó, la gente } \\
\text { casi no sabía ni leer ni escribir, el que } \\
\text { más sabía, había terminado primaria, } \\
\text { entonces, lógicamente, había que con- } \\
\text { tratar personas que tuvieran más cono- } \\
\text { cimientos y eran todos empleados" }\end{array}$ & $\begin{array}{l}\text { Características del entorno: } \\
\text { Oferta educativa: "No contar en la } \\
\text { comunidad con una institución califi- } \\
\text { cada, para poder estudiar le toca a uno } \\
\text { desplazarse del pueblo a la ciudad" }\end{array}$ \\
\hline $\begin{array}{l}\text { Estado de salud: "Todas las personas } \\
\text { aquí son muy capaces de hacer de todo; } \\
\text { es lógico que hay personas que no pue- } \\
\text { den por muchas razones, otras por } \\
\text { enfermas" }\end{array}$ & $\begin{array}{l}\text { Relaciones entre los asociados y los diri- } \\
\text { gentes } \\
\text { Confianza: "La gerente es muy abierta a } \\
\text { cualquier situación que pase en la coo- } \\
\text { perativa y los compañeros le tienen con- } \\
\text { fianza para decirle las cosas" } \\
\text { Distanciamiento: "Con el gerente que } \\
\text { tenemos no nos entendemos lo sufi- } \\
\text { ciente, no tenemos como esa confianza } \\
\text { con él" } \\
\text { Situación económica: } \\
\text { "Hubo una época que fue muy buena, } \\
\text { cuando había plata y se repartía, (...) } \\
\text { ahora, estamos en un proceso (situación } \\
\text { económica) muy difícil" }\end{array}$ & $\begin{array}{l}\text { Oferta laboral: "Los (asociados) que lle- } \\
\text { gan inicialmente se vinculan no por el } \\
\text { modelo (cooperativo), sino por cubrir } \\
\text { una necesidad de trabajar" }\end{array}$ \\
\hline
\end{tabular}


